\title{
Wegsuchen und Wegfindungen \\ Die christlichen Kirchen im Freistaat Sachsen seit 1990
}

\author{
Gerhard Lindemann
}

Sachsen verfügt über eine ausgeprägte religiöse Landschaft. Am mitgliederstärksten ist die Evangelisch-Lutherische Landeskirche Sachsens, deren Kirchengebiet mit dem Territorium des früheren Königreichs Sachsen identisch ist. Im Nordosten des Freistaats bestand darüber hinaus als deutsches Restgebiet der ehemaligen schlesischen Provinzialkirche, die zur Evangelischen Kirche der altpreußischen Union gehörte, im preußischen Anteil der Oberlausitz die Evangelische Kirche des Görlitzer Kirchengebietes, seit 1992 Evangelische Kirche der Schlesischen Oberlausitz mit zuletzt 72 Gemeinden. Sie fusionierte zum 1. Januar 2004 mit der ebenfalls unierten Evangelischen Kirche in Berlin-Brandenburg zur Evangelischen Kirche Berlin-Brandenburg-schlesische Oberlausitz (EKBO). Die evangelischen Christen in den Teilen des heutigen Nordsachsens, die 1815 unter preußische Hoheit kamen, gehörten der Evangelischen Kirche der Kirchenprovinz Sachsen an, die zum 1. Januar 2009 in der
Evangelischen Kirche in Mitteldeutschland (EKM) aufging. Überdies gibt es evangelischreformierte Gemeinden in Chemnitz, Leipzig und Dresden und eine Reihe von evangelischen Freikirchen, darunter Baptisten, Methodisten und die Herrnhuter Brüdergemeine, mit besonderer Verwurzelung im Erzgebirgsraum, im Vogtland und in der Oberlausitz.

Das römisch-katholische Bistum DresdenMeißen umfasst große Gebiete Sachsens und einen Teil Ostthüringens. Die Katholiken im ehemals preußischen Anteil der Oberlausitz gehören zum Bistum Görlitz, bis 1994 Apostolische Administratur Görlitz, die 1972 vom Bistum Breslau abgetrennt worden war. Das nordsächsische Gebiet ist dem Bistum Magdeburg zugeordnet.

Das öffentliche Bild der Kirchen, insbesondere in den Medien, aber auch in der überregionalen Wahrnehmung, wird stark durch die Bischöfe bestimmt - für den Berichtszeitraum in der lutherischen Landeskirche Johannes Hempel

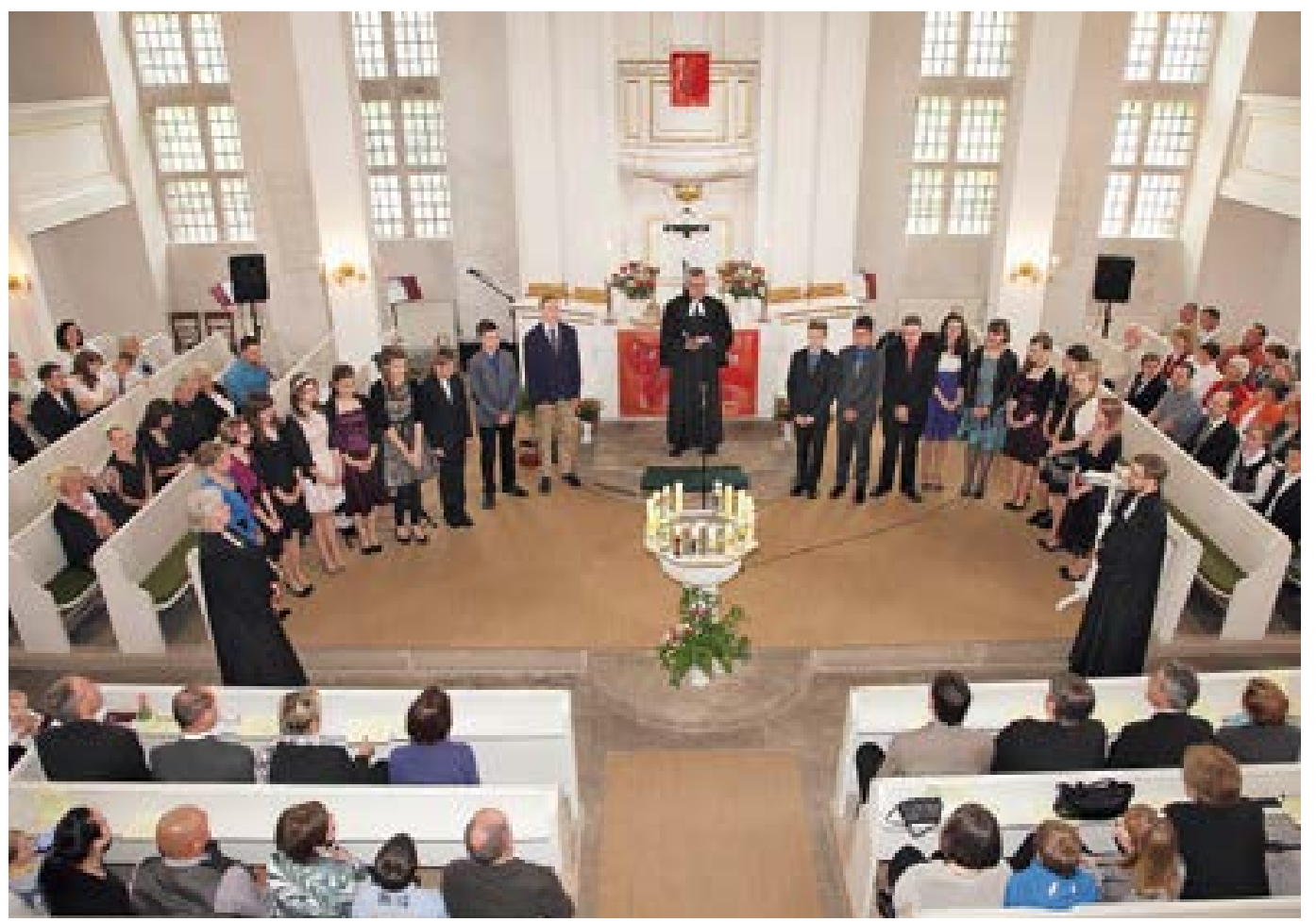


(bis 1994), Volker Kreß (bis 2004), Jochen Bohl (bis 2015), dem Carsten Rentzing nachfolgte (Amtseinführung am 29. August 2015), im Bistum Dresden-Meißen die Bischöfe Joachim Reinelt (bis 2012) und Heiner Koch (2013 bis 2015) sowie Weihbischof Georg Weinhold (bis 2008).

\section{Demokratische Wegbereitungen}

Insbesondere die lutherische Landeskirche, die Görlitzer Kirche und einige evangelische Freikirchen hatten während der SED-Herrschaft durch demokratisch gewählte sowie nach den Regeln des Parlamentarismus arbeitende Gremien ihren Mitgliedern Möglichkeiten der Einübung in demokratische Willensbildungsund Gestaltungsprozesse eröffnet. Seit den späten 1970er Jahren griff die sächsische Landessynode zunehmend Themenkomplexe auf, die gesellschaftliche Tabus berührten. Die Landeskirche wurde damit mehr und mehr zu einem Ersatzraum für den von Staat und Partei verweigerten innergesellschaftlichen Dialog. Vor allem in den großen Städten öffneten zumeist lutherische Kirchgemeinden ihre Räumlichkeiten für politisch-alternative Arbeitskreise. Hier setzten sich Christen und Nichtchristen mit den Themenkomplexen Frieden, Ökologie, Menschenrechte und „Dritte Welt" auseinander. Diese sogenannten Initiativoder auch Basis-Gruppen bildeten eine Wurzel der späteren Bürgerbewegung.

Ihre Themen und Positionen gingen in die Abschlusspapiere der DDR-weiten Ökumenischen Versammlung für Frieden, Gerechtigkeit und Bewahrung der Schöpfung 1988/89 ein. Daran beteiligten sich auch die römischkatholische Kirche, elf evangelische Freikirchen und weitere religiöse Gemeinschaften. Zwei der drei Tagungen fanden in Dresden statt. In der Folge entstand in der Elbmetropole das Ökumenische Informationszentrum, das für Dresden und Umgebung zu den Themenfeldern der Versammlung thematische Bildungsarbeit, Materialien und Arbeitshilfen, Beratung, Begegnungsmöglichkeiten und Räumlichkeiten für ehrenamtliche Gruppen und andere Organisationen anbietet sowie langfristige Projekte verfolgt (z. B. den christlich-islamischen Dialog oder einen Dialog der Kulturen).

Von den „Gruppen“ ging eine breite Kontrolle der Stimmauszählung bei den Kommunalwahlen am 7. Mai 1989 aus. Bereits im Vorfeld der Wahlen hatte die sächsische Landessynode Änderungen am Wahlverfahren gefordert und auch eine geheime Stimmabgabe oder gar eine Nichtteilnahme an der Wahl als für Christen mögliche Handlungsoptionen bezeichnet. Der gelungene konkrete Nachweis einer Nichtübereinstimmung zwischen den Auszählungen in den Wahllokalen und den offiziell in den DDR-Medien bekanntgegebenen Ergebnissen führte $\mathrm{zu}$ einem großen Legitimationsverlust des SED-Regimes.

In der Herbstrevolution 1989 waren die Kirchen ein wichtiger Faktor. In der Folge moderierten sie die Runden Tische, die auf der Bezirks-, Kreis- und lokalen Ebene bis $\mathrm{zu}$ freien Wahlen den Übergang von der Diktatur zur parlamentarischen Demokratie in die Wege zu leiten hatten. ${ }^{1}$

\section{Das Verhältnis der Kirchen zum \\ Freistaat Sachsen und ihre Positionierung in der politischen Öffentlichkeit}

Am 3. Oktober 1990, dem offiziellen Tag der Vereinigung der beiden deutschen Staaten, hielt Landesbischof Hempel eine der beiden Predigten im offiziellen Festgottesdienst in der (Ost-) Berliner Marienkirche. In seinen Dankadressen nannte er an erster Stelle die Demonstranten des Herbstes 1989 und gleich danach die kirchlichen Friedensgebete sowie die sogenannten „Gruppen“. Zugleich benannte er konkrete Sorgen der Gegenwart, unter anderem Arbeitslose, neue Selbständige mit schlechter Auftragslage, das Erbe der Staatssicherheit oder Kritik an dem Vereinigungsprozess der Kirchen, der manchen zu schnell ging: „Uns liegt auf dem Herzen die von vielen Menschen herbeigesehnte und doch auch gefürchtete westdeutsche Überlegenheit auf fast allen Gebieten. Wird von unserer in und trotz DDR entstandenen Lebens- und Denkungsart etwas übrigbleiben oder ändert sich alles?" ${ }^{\text {" Damit }}$ artikulierte er bange Fragen vieler Ostdeutscher. Viele Kirchgemeinden verzichteten auf ein Glockengeläut zur Feier der deutschen Einheit, weil man keine religiöse Legitimationsinstanz des Staates sein wollte. ${ }^{3}$

Der sächsische Landtag tagte bis zur Fertigstellung des neuen Parlamentsgebäudes zum 3. Oktober 1993 im Haus der Kirche (Dreikönigskirche) in Dresden. Vor der konstituierenden Sitzung des Parlaments am 27. Oktober 1990 fand in der Kreuzkirche ein ökumenischer Gottesdienst statt. ${ }^{4}$ Ein große Zahl von Christen engagierte sich in der Politik, im Vergleich zu anderen Landeskirchen waren es in Sachsen jedoch nur wenige evangelische Pfarrer. Viele sahen ihren gesellschaftlichen Dienst in der Umbruchs- und Übergangsphase nur als einen vorübergehenden an. ${ }^{5}$ Ein weiterer Grund für die Zurückhaltung der Amtsträger wird darin zu sehen sein, dass 


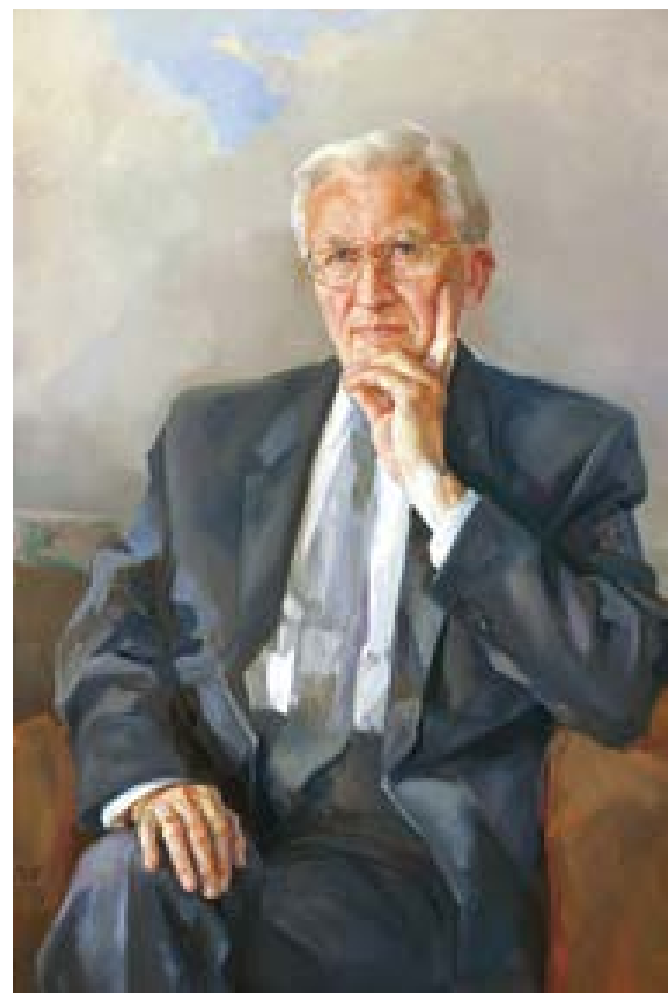

die lutherische Landeskirche zunächst von kirchlichen Mitarbeitern, die hauptamtlich ein politisches Mandat oder Amt übernahmen, einen Antrag auf Entlassung aus dem kirchlichen Dienst, von Pfarrern die Rückgabe ihrer Ordinationsurkunde forderte. Eine Rückkehr in das kirchliche Beschäftigungsverhältnis galt als möglich, allerdings nur, sofern eine Kirchgemeinde bereit war, sie auch anzustellen. ${ }^{6}$ Im November 1992 erfolgte eine Abmilderung dieser Bestimmungen. Seitdem ruht während der Wahrnehmung des politischen Mandats das kirchliche Dienstverhältnis - bei einer Mitgliedschaft in einer Kommunalvertretung kann es sogar in der Regel weiter bestehen, allerdings haben Pfarrer zuvor den Kirchenvorstand $\mathrm{zu}$ konsultieren. ${ }^{7}$ Damit trug man einerseits den Spezifika der Friedlichen Revolution Rechnung, zum anderen darf nach Artikel 48 des Grundgesetzes kein Bürger an der Übernahme eines Abgeordnetenmandats gehindert werden. ${ }^{88}$ Angesichts eines sich abzeichnenden Übergewichts katholischer Christen „in den führenden Positionen“ - als Ministerpräsident war Kurt Biedenkopf, als Landtagspräsident Ordinariatsrat Erich Iltgen, neben Pfarrer Martin Lerchner Moderator des Runden Tisches des Bezirks Dresden, vorgesehen, Dresdens Oberbürgermeister war der Katholik Herbert Wagner, ein Mitglied der „Gruppe der 20“ - hoffte Hempel, wie er bei einem Besuch des designierten Ministerpräsidenten in seiner Dresdner Wohnung am 19. Oktober 1990 erklärte, auf eine

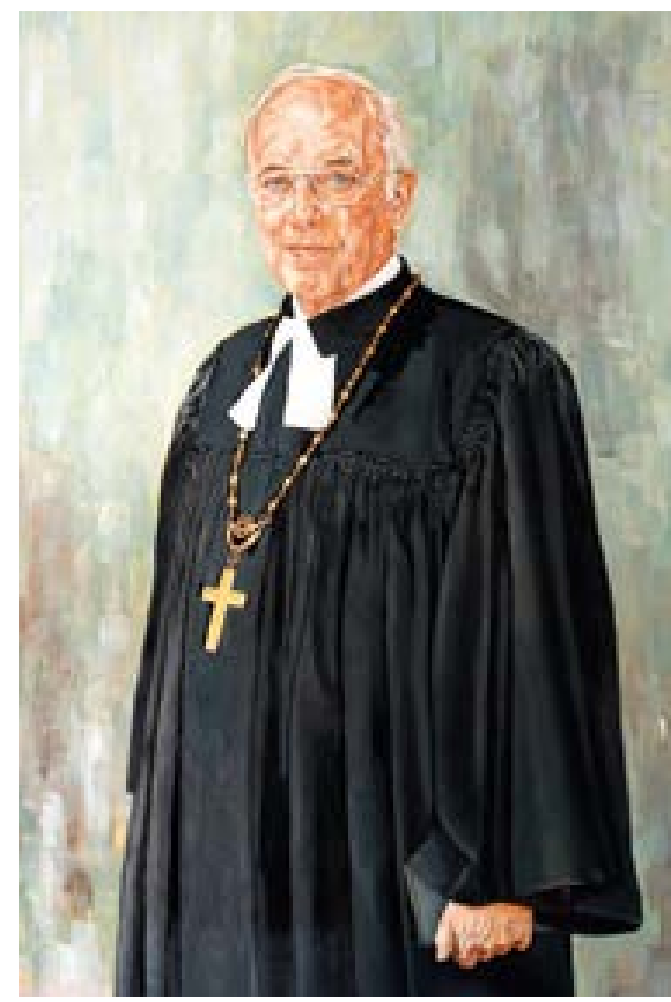

Besetzung des für die Schulpolitik zuständigen Ministeramtes mit einem Protestanten. ${ }^{9}$ Daraufhin teilte Biedenkopf das geplante Ressort für Unterricht, Wissenschaft und Kultur und besetzte das Kultusministerium mit der lutherischen Christin Stefanie Rehm, zugleich seit 1969 Mitglied der Ost-CDU. ${ }^{10}$ Wissenschaftsminister wurde Hans-Joachim Meyer, langjährig aktiv in der katholischen Laienbewegung, unter anderem

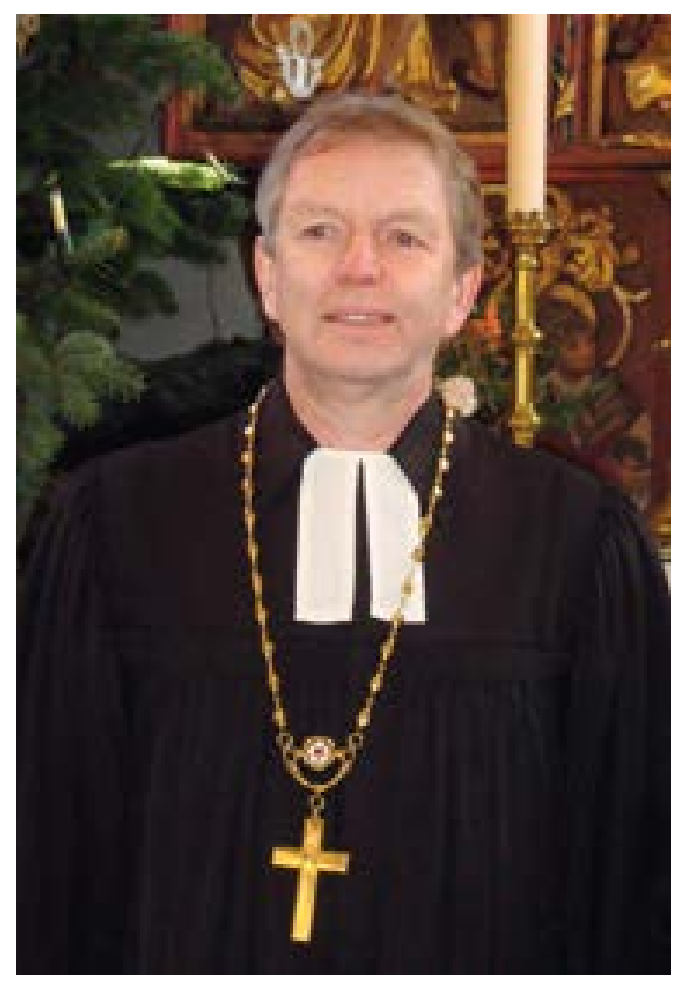

Dr. Dr. h.c. Johannes Hempel, Landesbischof der EvangelischLutherischen Landeskirche Sachsens von 1972 bis 1994, Gemälde von Christoph Wetzel, 2003

(C) Evangelisch-Lutherische Landeskirche Sachsens

Volker Kreß, Landesbischof der Evangelisch-Lutherischen Landeskirche Sachsens von 1994 bis 2004, Gemälde von Ursula Wieland, 2006 (C) Evangelisch-Lutherische Landeskirche Sachsens

Jochen Bohl, Landesbischof der Evangelisch-Lutherischen Landeskirche Sachsens von 2004 bis 2015

Foto: wikimedia 
11 Vgl. Hempel, Kirche (wie Anm. 2), S. 233.

12 Vgl. ebd., S. 250.

13 Vgl. Volker Kreß, Zur Lage der evangelischen Kirche in den neuen Bundesländern sechs Jahre nach der Wiedervereinigung Deutschlands, in: Amtsblatt 1996, S. B 100; ders., Vom Wunsch und der Aufgabe, sich einzumischen, in: Amtsblatt 2000, S. B 5.

$14 \mathrm{Vgl}$. Kirche in der Mitte der Gesellschaft (wie Anm. 5), S. B 18 f.

15 Hempel, Kirche (wie Anm. 2), S. 225.

16 Vgl. ebd., S. 226; 227

17 Vgl. Johannes Hempel, „Stellungnahme zu uns selbst“. Wider die einfachen Antworten, in: Amtsblatt 1992, S. B 48.

18 Art. 109, Abs. 1.
Joachim Reinelt, Bischof des katholischen Bistums DresdenMeißen von 1988 bis 2012 (C) Bistum Dresden-Meißen

Heiner Koch, Bischof des katholischen Bistums DresdenMeißen von 2013 bis 2015, jetzt Erzbischof von Berlin (c) Bistum Dresden-Meißen hatte er der von 1973 bis 1975 in Dresden tagenden Pastoralsynode der Jurisdiktionsbezirke der katholischen Kirche in der DDR angehört, die Impulse des Zweiten Vatikanischen Konzils aufnahm. Seit 1990 war er im reformkatholischen Zentralkomitee der deutschen Katholiken engagiert, von 1997 bis 2009 als dessen Präsident. Dem Kabinett Biedenkopf gehörten ausschließlich Mitglieder der beiden "großen“ Kirchen an.

Im Oktober 1991 erklärte Hempel, das aktive politische Engagement katholischer Laien sei „nach ,Plötzlichkeit' und Ausmaß (Menge) überraschend" gekommen, sollte jedoch nicht Grund zur Klage, sondern für Protestanten ein Ansporn sein. ${ }^{11}$ Politiker, unter anderem Ministerpräsident Biedenkopf, ermunterten die evangelische Landeskirche, sich stärker für eine Mitarbeit in der neuen Gesellschaft zu öffnen ${ }^{12}$, damit war ein zu persönlichem gesellschaftlichen Engagement ermutigendes und bisweilen auch beruhigendes SichEinbringen gemeint. ${ }^{13}$ Allerdings machte man kirchlicherseits auch die Erfahrung, dass aufgrund der Vielstimmigkeit in der pluralen Gesellschaft und der Medienvielfalt manche Verlautbarungen in der Öffentlichkeit und bei ihren Adressaten nicht rezipiert wurden. ${ }^{14}$

Der kirchliche Übergang und Neubeginn im demokratischen Verfassungsstaat stand $\mathrm{zu}^{-}$ nächst unter dem Leitwort der "Wegsuche“. ${ }^{15}$ Im Oktober 1991 betonte Johannes Hempel vor der Landessynode, demokratische Wahlen und

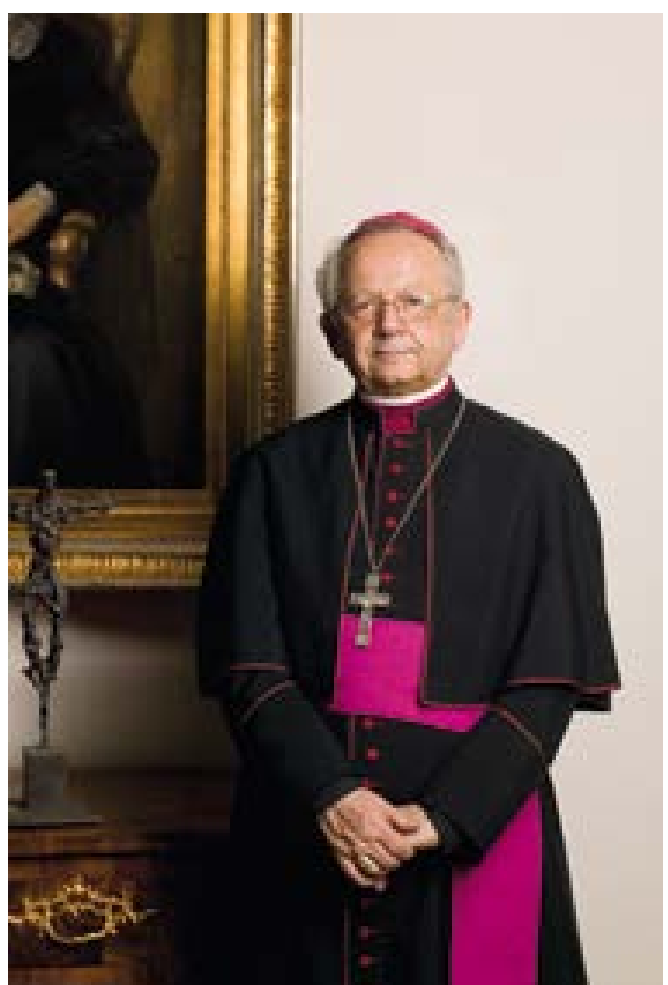

Kontrollmöglichkeiten, Rechtsstaatlichkeit und individuelle Freiheiten seien verglichen mit der überwundenen SED-Herrschaft eindeutige Vorteile der neuen Gesellschaftsordnung. Frei gewählte Politiker mit parlamentarischer Ein- oder zumindest Rückbindung und im allgemeinen größeren sachlichen und fachlichen Kompetenzen sowie ein beträchtlicher Anteil von Kirchenmitgliedern unter den politisch Verantwortlichen ließen ein besseres und freundlicheres Staat-Kirche-Verhältnis erwarten. ${ }^{1616}$ Dennoch sollte, so der Bischof, die Kirche, wo es notwendig erscheine, konstruktive Kritik an politischen Entscheidungen üben oder auf gesellschaftliche Probleme aufmerksam machen. ${ }^{17}$

Die sächsische Verfassung von 1992 wies den Kirchen und Religionsgemeinschaften eine „Bedeutung für die Bewahrung und Festigung der religiösen und sittlichen Grundlagen des menschlichen Lebens " $\mathrm{zu}^{18}$. In der Folge ging es um die nähere Ausgestaltung des zwischen Staat und Kirche bestehenden Rechtsverhältnisses: Am 24. März 1994 wurde im Haus der Kirche in der Dresdner Dreikönigskirche für die evangelischen Landeskirchen der „Evangelische Kirchenvertrag Sachsen“ unterzeichnet. Im gleichen Jahr folgte ein Staatsvertrag mit den Jüdischen Gemeinden, 1996 schloss der Freistaat mit dem Heiligen Stuhl für das Bistum Dresden-Meißen ein Konkordat ab. Die Vertragswerke stehen für ein partnerschaftliches Verhältnis von Staat und Kirchen

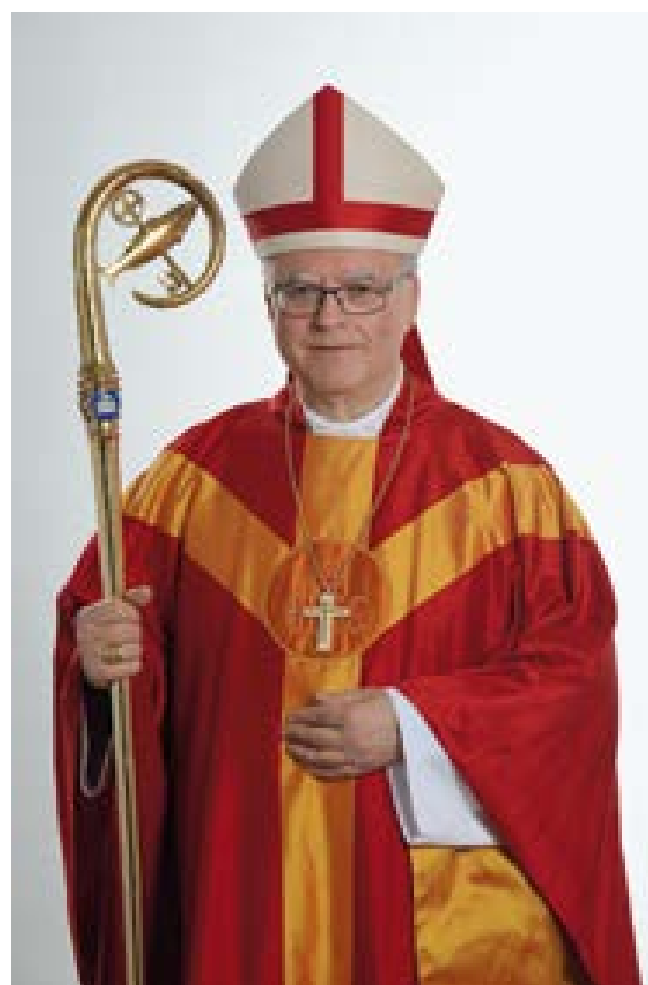


sowie jüdischen Gemeinden. Besondere Anerkennung finden deren Eigenständigkeit und ihr Öffentlichkeitsauftrag. ${ }^{19}$

Bereits 1990 und 1991 richteten die Kirchen ein Katholisches Verbindungsbüro bzw. das Amt eines Beauftragten der evangelischen Landeskirchen beim Freistaat Sachsen ein. Die in der DDR gestrichenen kirchlichen Feiertage Ostermontag, Christi Himmelfahrt, der Reformationstag und der Buß- und Bettag - letzterer seit der bundesweiten Abschaffung 1995 in Sachsen als einzigem Bundesland, allerdings für Arbeitnehmerverbunden mit einem Zusatzbeitrag für die Pflegeversicherung - wurden wieder zu staatlich geschützten Feiertagen.

Landesbischof Kreß bezeichnete im November 1996 vor der Landessynode, die am 12. Mai 1996 mit der Hotelfachfrau Gudrun Lindner erstmals eine Frau in ihr Präsidialamt gewählt hatte, Christen und die Kirchen im Sinne der - hier aber nicht konkret erwähnten-Demokratiedenkschrift der Evangelischen Kirche in Deutschland (EKD) von 1985 als „Mitgestalter dessen, was man den ,Staat' nennt“20 Daraus entwickelte die sächsische Kirchenleitung im Herbst 1998 unter der Aufnahme des Paradigmas von der offenen Gesellschaft ${ }^{21}$ das Leitwort „Kirche in der Mitte der Gesellschaft“22 Die Landeskirche verstand sich als „Kirche für das Volk“ und in dem Sinne weiterhin als Volkskirche sowie als „Kirche in der Öffentlichkeit der Lebensprozesse und Auseinandersetzungen [...], Kirche in der öffentlichen Verantwortung“. Als solche habe sie Position zu beziehen $\mathrm{zu}$ den „Lebensfragen des Volkes" - damit erinnerte man an den 1968 gestrichenen Artikel 41 (2) der DDR-Verfassung von 1949 - „und sich kritisch-konstruktiv zu beteiligen an der gesellschaftlichen Entwicklung“23 Ein Jahr später hieß es, man wolle Kirche nahe bei allen Menschen sein, mit sachlich kompetenter Präsenz an den gesellschaftlichen Brennpunkten, bei ungelösten Zeitfragen, zugleich geistlich kompetent die „Mitte der Gesellschaft“ mitbestimmend und -gestaltend. ${ }^{24}$

Zunehmend erwartete die Politik von den Kirchen ein werte- und sinnstiftendes Agieren, womit aber eher eine "gut-bürgerliche“ Moral als konkrete Glaubensaussagen gemeint war. ${ }^{25}$ Diese Erwartungshaltung hing nach Deutung der Landeskirche auch mit den großen Umbrüchen in der Gesellschaft ${ }^{26}$ und einer noch bis heute eher schwachen Zivilgesellschaft zusammen.

Klare Abgrenzungen gab es seitens beider Kirchen von der 2004 mit 9,2 Prozent der abgegebenen Stimmen erstmals in den Landtag eingezogenen NPD, der, wie Landesbischof Jochen Bohl vor der Landessynode beklagte, offenbar auch evangelische Christinnen und Christen ihre
Stimme gegeben hatten. Bohl erklärte vor den Medien, eine rassistische Weltsicht sei mit dem christlichen Glauben unvereinbar. Zugleich empfahl er, mit christlichen NPD-Wählern, die sich zu dieser Entscheidung offen bekannten, zum Beispiel in Briefen an den Bischof, das Gespräch zu suchen. ${ }^{27} 2001$ bis 2010 begingen auch die in der Arbeitsgemeinschaft Christlicher Kirchen zusammengeschlossenen Kirchen Sachsens gemeinsam die Ökumenische Dekade zur Überwindung von Gewalt. 2005 entstand die ökumenische „AG Kirche für Demokratie gegen Rechtsextremismus“. Am 1. Februar 2009 rief die sächsische Kirchenleitung schließlich zur Beteiligung an dem Aktionsjahr „Nächstenliebe verlangt Klarheit. Kirche in Sachsen für Demokratie gegen Rechtsextremismus" auf. ${ }^{28}$ In einem Aufruf zur Landtagswahl 2009 erklärte die Landessynode: „Rechtsextreme Parteien wie die NPD sind für Christen nicht wählbar. Rassismus, Antisemitismus und Fremdenfeindlichkeit sind mit dem christlichen Glauben nicht vereinbar. Sie widersprechen der biblischen Botschaft von Gott als dem Schöpfer aller Menschen. Rechtsextremistische Anschauungen stehen im Widerspruch zum Versöhnungshandeln Jesu Christi, das allen Menschen gilt. Es bleibt unsere Aufgabe, Demokratie zu stärken und zu gestalten." 29

Landesbischof Bohl zeigte sich erleichtert, dass 2014 die NPD den Wiedereinzug in den Landtag knapp verpasste ${ }^{30}$, weitgehend unkommentiert, auch von Seiten der Kirchenleitung, blieb jedoch der Einzug der in Sachsen von Beginn an rechtspopulistisch agierenden Alternative für Deutschland (AfD) in das Landesparlament, unter deren Abgeordneten sich aktive Glieder der evangelischen Kirche befinden. Die AfD hatte während des Wahlkampfes in ähnlicher Weise wie die NPD vor allem in deren bisherigen Hochburgen mit gegen Asylbewerber gerichteten Plakaten für sich geworben und sich in ihrem Wahlprogramm unter anderem für Volksabstimmungen über den Bau von Moscheen ausgesprochen, was in einem diametralen Gegensatz zum im Grundgesetz verankerten Grundrecht auf Religionsfreiheit steht.

Angesichts der sich gegen eine von deren Initiatoren befürchtete Islamisierung des „Abendlandes“ richtenden Pegida-Demonstrationen sprach sich die lutherische Kirchenleitung, ebenso wie das katholische Bistum, im Dezember 2014 für eine „Willkommenskultur“ gegenüber Asylbewerbern aus. ${ }^{31}$ Dazu beschloss das Landeskirchenamt im Januar 2015 eine Richtlinie für Gemeinden. ${ }^{32}$ In seiner vorweihnachtlichen Predigt vor der Dresdner
19 Vollständiger Text in: Amtsblatt der Evangelischen Kirche in Deutschland 1994, S. 270-276.

20 Volker Kreß, Erkennbare Kirche, in: Amtsblatt 1997, S. B 1.

$21 \mathrm{Vgl}$. Kirche in der Mitte der Gesellschaft (wie Anm. 5), S. B 16.

22 Vgl. auch ebd., S. B 13-19.

23 Betrachtungen zum wirtschaftlichen und sozialen Handeln in Kirche und Diakonie und Überlegungen zum weiteren Weg der Kirche, in: Amtsblatt 1998, S. B 71.

24 Kirche in der Mitte der Gesellschaft (wie Anm. 5), S. B 16

25 So Volker Kreß, „Wenn aber kommen wird das Vollkommene, so wird das Stückwerk aufhören.", in: Amtsblatt 2000 S. B 82

26 Vgl. Volker Kreß, „Die Furcht des Herrn ist eine Quelle des Lebens.“, in: Amtsblatt 2003, S. B 57-60; hier: 57.

27 Vgl. Jochen Bohl, Bericht zur Herbsttagung der 25. Ev.-Luth. Landessynode Sachsens 2004 in: Amtsblatt 2004, S. B 50.

28 Text: Amtsblatt 2009, S. B 12.

29 Text: Amtsblatt 2009, S. B 32.

$30 \mathrm{Vgl}$. Landesbischof Bohl zum Wahlergebnis der Landtagswahl in Sachsen (http://www.evlks. de/aktuelles/nachrichten/24811. html; Zugriff 11.8.2015).

$31 \mathrm{Vgl}$. http://www.evlks.de/doc/ Wort_der_Kirchenleitung vom 5. Dezember 2014.pdf (Zugriff 11.8.2015).

$32 \mathrm{Vgl}$. http://www.evlks.de/aktuelles/themen/14895 25846.html (Zugriff 14.8.2015). 
$33 \mathrm{http}: / /$ www.evlks.de/landeskirche/landesbischof/25698.html (Zugriff 11.8.2015).

34 Folkert Ihmels, Wünsche eines Scheidenden an und für seine Kirche, in: Amtsblatt 1994, S. B 13.

35 Vgl. Ihmels, An der Schwelle (wie Anm. 6), S. B 66.

36 Vgl. Hempel, Kirche (wie Anm. 2), S. 221 f. Vgl. auch die Kritik von Pfarrer Johannes Berthold, Borstendorf, in: Amtsblatt 1990, S. B 87.

37 Vgl. Ihmels, An der Schwelle (wie Anm. 6), S. B 66.

$38 \mathrm{Vgl}$. Wolfgang Ratzmann, Wozu jetzt noch Kirche? Überlegungen zum kirchlichen Dienst heute, in: Amtsblatt 1993, S. B 57.

39 So Hans-Dieter Hofmann, Angst um die Kirche?, in: Amtsblatt 1996, S. B 47.

40 Vgl. Ihmels, An der Schwelle (wie Anm. 6), S. B 67.

$41 \mathrm{Vgl}$. auch Kirche in der Mitte der Gesellschaft (wie Anm. 5), S. B 15.

$42 \mathrm{Vgl}$. Die zurückliegenden fünf Jahre und der weitere Weg unserer Kirche, in: Amtsblatt 2001, S. B 86.

43 Vgl. Richter, Die Bildung (wie Anm. 4), S. $584 \mathrm{f}$

44 Vgl. Presseerklärung des Ev.Luth. Landeskirchenamtes zur Frage des Religionsunterrichtes, in: Der Sonntag, Nr. 12, 24.3.1991, S. 1
Frauenkirche erklärte Bohl, bei Pegida gehaltene Reden „schürt[en] Ängste, für die es keinen realen Grund gibt. [...] Jesus hat einmal gesagt und sich unmissverständlich ausgedrückt: In den Hungrigen, den Flüchtlingen, den Kranken begegnen wir Ihm selbst (Matthäus 25, 43-45). Darum sind wir Christinnen und Christen gebunden und können nicht anders, als denjenigen $\mathrm{zu}$ widersprechen, die anderes wollen, was nicht christlich wäre. Morgen beginnt das Christfest, an dem das Licht aus der Höhe uns aufscheint. Christus kommt, damit wir zur Barmherzigkeit finden. ${ }^{\text {"33 }}$

\section{Neue gesellschaftliche Wirkungsmöglichkeiten}

Im Unterschied zu Staat und Gesellschaft waren die christlichen Kirchen nicht zu einem größeren institutionellen und personellen Neubeginn genötigt. Herausforderungen ergaben sich aus einer Anpassung an das Staat-Kirche-Verhältnis in der Bundesrepublik. Dies deutete sich bereits seit dem Frühjahr 1990 an und stieß innerhalb der ostdeutschen Kirchen schon deshalb auf Vorbehalte, weil man, bedingt durch die SEDHerrschaft, eine möglichst große Unabhängigkeit vom Staat zu schätzen gelernt hatte. Es kam vor allem in den evangelischen Landeskirchen $\mathrm{zu}$ „harten [...] Auseinandersetzungen“. ${ }^{34}$

Ein erster dringender Handlungsbedarf bestand, als im April 1990 die Arbeiten an einer neuen sächsischen Verfassung begannen. Die Kirchen forderten, auch auf die Bitte der westdeutschen Kirchen hin - dort gab es die Befürchtung, dass ein Abweichen von der bisherigen staatskirchenrechtlichen Stellung der Kirchen in der Bundesrepublik diese langfristig auch in den westlichen Bundesländern gefährden würde ${ }^{35}$ -, eine Verankerung des Status der Kirchen als Körperschaften des öffentlichen Rechts, des kirchlichen Rechts, Steuern zu erheben, und des Rechts auf schulischen Religionsunterricht im Verfassungstext. Der enge Zeitrahmen bedingte eine vor allem auf evangelischer Seite beklagte mangelnde Rückkoppelung der Kirchenleitungen mit der Mitarbeiter- und Gemeindeebene. ${ }^{36}$

Kritisiert wurde vor allem im evangelischen Bereich die Rückkehr zu volkskirchlichen Verhältnissen, ohne dass Erfahrungen der Freiwilligkeits- und Minderheitskirche in der DDR genügend Berücksichtigung fanden. Sollte man, wie der Dresdner Oberlandeskirchenrat Folkert Ihmels im Juni 1990 im hannoverschen Kirchensprengel Osnabrück fragte, Strukturen übernehmen, die, angesichts der dort ebenfalls fortschreitenden Entkirchlichung, wenn auch auf einem zahlenmäßig höheren Niveau als in der
DDR, auch im Westen irgendwann einmal schwer finanzierbar sein würden? Durch die Übernahme des westlichen Gehaltsgefüges würden kirchliche Mitarbeiter im Osten künftig finanziell deutlich besser als der Bevölkerungsdurchschnitt dastehen und als Profiteure des gesellschaftlichen Umbruchs gelten. ${ }^{37}$ Tatsächlich erschienen in der Folgezeit vielen Außenstehenden die größeren Kirchen als privilegiert, in ihren bald stärker an die westlichen Verhältnisse angepassten Strukturen als verwechselbar mit Verbänden oder dem Staat. ${ }^{38}$ Auf der anderen Seite gab es in den ostdeutschen Landeskirchen weiterhin volkskirchliche Elemente, an die sich nun anknüpfen ließ. Es hatte sich nicht um reine Freiwilligkeitskirchen gehandelt, sondern um „Minderheitskirchen in volkskirchlichen Strukturen“" ${ }^{39}$

Zum 1. Januar 1991 wurde das westliche Kirchensteuersystem eingeführt. Das dortige Einzugsverfahren auf der Grundlage der allgemeinen Steuerlisten wurde letztlich als gerechter als das bisherige empfunden, da es im Unterschied zum auf der nicht kontrollierbaren finanziellen Selbstauskunft der Mitglieder beruhenden ostdeutschen Verfahren die jährlichen Einnahmen der Steuerpflichtigen konkret erfasste. Jedoch blieben Bedenken, ob dieses System die Besonderheiten der ostdeutschen Situation aufgrund der häufig niedrigen Gehälter, der verbreiteten Arbeitslosigkeit und desweitgehenden Fehlensvon sogenannten „Großverdienern“ in den christlichen Gemeinden genügend berücksichtigte. ${ }^{40}$ Letztlich knüpfte zusätzlich zur Kirchensteuer ein durch die Gemeinden eingetriebenes Kirchgeld an das bisherige, weniger anonyme Einzugssystem und die dadurch gewachsene Bereitschaft einiger Gemeindeglieder an, ein größeres $\mathrm{Ma}$ an finanzieller Mitverantwortung für die Kirche zu übernehmen. ${ }^{41}$ In den ersten Jahren nach der Währungsumstellung waren entgegen allen Befürchtungen die Kirchensteuereinnahmen jedoch deutlich ansteigend. ${ }^{42}$

Noch kontroverser war zunächst ein weiteres Feld: Bereits während der Erarbeitung der neuen sächsischen Verfassung setzten sich im Juli 1990 die Kirchen für eine Wiedereinführung des schulischen Religionsunterrichts ein. Dagegen gab es nicht nur innerkirchliche Widerstände.

So plädierte der Vorsitzende des Koordinierungsausschusses zur Bildung des Landes Sachsen, Arnold Vaatz, für eine Beibehaltung der von den Kirchen verantworteten Christenlehre. ${ }^{43}$ Kultusministerin Rehm sprach sich im März 1991 für einen freiwilligen schulischen Religionsunterricht in kirchlicher Verantwortung als eine mögliche Ergänzung zu dem obligatorischen Fach „Philosophie und Ethik“ aus. Das stieß unter Verweis auf das Grundgesetz auf einen energischen kirchlichen Protest. ${ }^{44}$ 
Innerkirchliche Kritiker des Religionsunterrichts befürchteten eine staatliche Bevormundung und einen Verlust der kirchlichen Eigenständigkeit im Bereich der Religionspädagogik, die Ablösung des unbeliebten Faches Staatsbürgerkunde durch ein neues Weltanschauungsfach und eine diesen von ihren Mitgliederzahlen her nicht zustehende Vorzugsposition der Kirchen. Im Hintergrund standen angesichts der geringen personellen Veränderungen in der Lehrerschaft auch Ängste aufgrund vielfacher persönlicher Ausgrenzungserfahrungen als christliche Schüler oder Eltern durch das DDR-Volksbildungssystem..$^{45}$ Tatsächlich gab es in der Folgezeit eine Reihe von Fällen, in denen Pfarrer oder andere kirchliche Mitarbeiter, die schulischen Religionsunterricht erteilten, in den Lehrerkollegien Weiterwirkungen des religionsfeindlichen Klimas in der DDRVolksbildung begegneten. ${ }^{46}$

Der Freistaat Sachsen sah im 1992 gemeinsam mit dem Wahlpflichtfach Ethik eingeführten Religionsunterricht auch einen kirchlichen Beitrag zur innergesellschaftlichen Wertebildung. Die Kirchen wollten den Heranwachsenden Hilfestellungen geben, „um den Fragen und Aufgaben des Lebens zu begegnen“, und zugleich BrückenzudenGemeindenbauen. ${ }^{47}$ DerUnterricht informiert über die christliche Tradition und ihre Wurzeln im Judentum, vermittelt die Kompetenz zu einer eigenständigen Auseinandersetzung mit dem christlichen Glauben, ist damit offen für konstruktiv-kritisches Fragen und Nachdenken, gibt Anregungen zu einer christlichen Lebensgestaltung und bietet den Schülerinnen und Schülern schließlich auch Lebenshilfe und Begleitung an. ${ }^{48}$ Auch die Lehrpläne des Faches Ethik enthalten christliche Inhalte. ${ }^{49}$

Zum 1. Juli 2014 nahmen in Sachsen 25,6 Prozent aller Schüler am evangelischen Religionsunterricht teil. Das liegt über dem Anteil der Kirchenmitglieder ${ }^{50}$, allerdings ist der Anteil der nicht getauften Schüler im Vergleich zu den Anfangsjahren mittlerweile gesunken. ${ }^{51}$ Immer noch erfolgt der Unterricht mit Ausnahme der gymnasialen Oberstufe in der Regel ${ }^{52}$ lediglich mit einer statt der in der Stundentafel vorgesehenen zwei Wochenstunden. Bisweilen übergreifen Lerngruppen mehrere Jahrgänge mit bis zu 28 Schülern, so dass das Landeskirchenamt 2014 von einer Stagnation bis hin zu einer Verschlechterung der Lage sprach. ${ }^{53}$

Besonders umstritten war die Frage der $\mathrm{Mi}$ litärseelsorge. Während der SED-Diktatur hatten Geistliche keinen Zutritt zu den Kasernen der Nationalen Volksarmee gehabt. Soldaten konnten kirchliche Angebote nur während ihres Ausgangs aus der Kaserne oder im Urlaub in Anspruch nehmen. In den westlichen Bundesländern galt seit
1957 ein zwischen der Regierung Adenauer und der EKD abgeschlossener Militärseelsorgevertrag. Dieser war von Beginn an innerkirchlich umstritten - er garantierte den Kirchen freien Zugang zu den Einrichtungen der Bundeswehr, machte jedoch im Gegenzug die dafür zuständigen Geistlichen zu Staatsbeamten. Während die katholische Kirche in Ostdeutschland keine öffentliche Debatte um diese Thematik führte, gab es im evangelischen Bereich eine Reihe von Anfragen, neben der Kritik an dem Beamtenstatus der Militärseelsorger auch der Gesichtspunkt, dass friedensethische Reflexionen während der DDR-Zeit zu einer theologischen Infragestellung des Krieges als Mittel der politischen Konfliktlösung geführt hatten. 1991 gestattete das Bundesverteidigungsministerium für den Zeitraum von zunächst zwei Jahren der evangelischen Kirche in den neuen Bundesländern eine nebenamtliche Soldatenseelsorge durch die zuständigen Ortsgeistlichen. An den acht Bundeswehrstandorten in Sachsen wurde in der Folgezeit unter zusätzlicher Einbeziehung von Diakonen entsprechend verfahren. ${ }^{54}$

Eine Rahmenvereinbarung für den Bereich der östlichen Bundesländer vom Juli 1996 gestand dort übergangsweise den Militärseelsorgern den Status von Kirchenbeamten zu, seit Anfang 2004 gilt auch hier der Militärseelsorgevertrag in seiner ursprünglichen Fassung uneingeschränkt ${ }^{55}$, dem hatte die sächsische Landessynode im April 2003 zugestimmt. $^{56}$ Parallel engagierten sich beide Kirchen in der Beratung und Begleitung von Zivildienstleistenden.

Die verbreitete Zurückhaltung gegenüber kirchlichen Kooperationsmöglichkeiten mit dem Staat hing auch damit zusammen, dass die über 40-jährige Erfahrung des eher feindlichen Gegenübers der SED-Herrschaft, die an christlicher Mitgestaltung, wenn überhaupt, nur affirmativ interessiert war, weiterhin Mentalitäten prägte. ${ }^{57}$ Es brauchte bei dem einen oder anderen etwas Zeit, den demokratischen Verfassungsstaat als ein Angebot zur bürgerschaftlichen Mitwirkung zu begreifen und dann auch entsprechend mit Leben zu erfüllen.

Die katholische Kirche hatte bei diesen Fragen weniger Vorbehalte, was mit ihrem Auftreten mit dem Selbstverständnis als Weltkirche ${ }^{58}$, aber wohl auch mit einer geringeren institutionalisierten innerkirchlichen Debattenkultur zusammengehangen haben mag. Trotz aller Vorbehalte wuchs im Lauf der Zeit bei beiden christlichen Konfessionen die Wertschätzung der vielfältigen Möglichkeiten $\mathrm{zu}$ einer größeren öffentlichen Wirksamkeit und der damit verbundenen Chance, über die sogenannten Kerngemeinden hinaus einen
45 Vgl. Helmut Hanisch, Im Schnittpunkt von Indifferenz und Affirmation. Anmerkungen zum Religionsunterricht im Freistaat Sachsen, in: Friedrich Schweitzer (Hg.), Der Bildungsauftrag des Protestantismus, Gütersloh 2002, S. 145-163; hier: $153 \mathrm{f}$.

46 Vgl. Klaus Tanner, Bildungsauftrag und öffentliche Bildungsverantwortung der Kirche in der Wissensgesellschaft, in: Amtsblatt 2001, S. B 65.

47 Tätigkeitsbericht der Kirchenleitung für die Herbstsynode 1992, in: Amtsblatt 1993, S. B 1.

48 Vgl. auch Tätigkeitsbericht des Evangelisch-Lutherischen Landeskirchenamtes Sachsens 2013/14, S. 41 (http://www evlks.de/doc/VL_07 TTB LKA_2013_14.pdf; Zugriff 14 $8.2015)$.

49 Vgl. Tanner, Bildungsauftrag (wie Anm. 46), S. B 65.

50 Vgl.auch Tätigkeitsbericht2013/ 14 (wie Anm. 48), S. 43.

51 Vgl. Christoph Gramzow/Helmut Hanisch, Schlussfolgerungen, in: dies. (Hg.), Das Fach Evangelische Religion im Freistaat Sachsen aus der Sicht der Unterrichtenden. Ergebnisse einer empirischen Untersuchung und eines Symposions, Leipzig 2015, S. 250-258; hier: 257.

52 So ebd., S. $250 \mathrm{f}$.

$53 \mathrm{Vgl}$. auch Tätigkeitsbericht 2013/14 (wie Anm. 48), S. 44.

54 Vgl. Volker Kreß, Seelsorge an Soldaten und Militärseelsorgevertrag - eine Problemskizze, in: Amtsblatt 1991, S. B 65-67; hier: $66 \mathrm{f}$

55 Vgl. Martin Greschat, Der Protestantismus in der Bundesrepublik Deutschland (19452005), Leipzig 2011, S. 209 f

$56 \mathrm{Vgl}$. Kirchliches Jahrbuch für die Evangelische Kirche in Deutschland (künftig: Kirchliches Jahrbuch) 2003, S. 585.

57 Vgl. Kreß, Zur Lage (wie Anm. 13), S. B 99

$58 \mathrm{Vgl}$. ebd. 
59 Tätigkeitsbericht der Kirchenleitung, in: Amtsblatt 1994, S. B 77.

60 Vgl. Tätigkeitsbericht der Kirchenleitung für die Herbstsynode 1992 (wie Anm. 47), S. B 2.

61 Vgl. Klaus Fitschen, Säkulares Reformationsland? Kirche, Religion und Gesellschaft in Sachsen, in: Konstantin Hermann (Hg.), Sachsen seit der Friedlichen Revolution. Tradition, Wandel, Perspektiven, Beucha/ Markkleeberg 2010, S. 199-209, hier: S. 208.

62 Vgl. z. B. Bericht zur Herbsttagung der 25. Ev.-Luth. Landessynode (wie Anm. 27), S. B 66.

$63 \mathrm{http}: / / \mathrm{www}$.evangelischeschulen-sachsen.de/schulen/; http://www.bistum-dresdenmeissen.de/front content. $\mathrm{t}=1$ \&lang $=1$ \&idcat $=1754 \quad(\mathrm{Zu}-$ griffe 18.8.2015)

64 Vgl. Tätigkeitsbericht 2013/14 (wie Anm. 48), S. 30

65 Vgl. ebd., S. 35 f.

$66 \mathrm{Vgl}$. bereits Hempel, Kirche (wie Anm. 2), S. $233 \mathrm{f}$. größeren Kreis von Menschen zu erreichen gemeindeferne Kirchenmitglieder, aber auch Religionslose. Als positiv wurde nun vielfach empfunden, dass Kirche „plötzlich wieder ein erwünschter Teil dieser Gesellschaft" war. ${ }^{59}$

Stark erweitert waren die kirchlichen Möglichkeiten in den Bereichen Krankenhaus- und Gefängnisseelsorge. Ein völliges kirchliches Neuland war die Polizeiseelsorge, wo Pfarrern der berufsethische Unterricht im Rahmen von Laufbahnseminarenübertragen wurde. ${ }^{60} \mathrm{Neuin}$ stalliert wurde auch die Notfallseelsorge.

Beide Kirchen engagieren sich im Bildungsbereich: Evangelische und katholische Schulen wurden wieder gegründet oder entstanden neu, darunter das Evangelische Kreuzgymnasium und das katholische St. BennoGymnasium in Dresden oder das ebenfalls katholische Maria-Montessori-Schulzentrum in Leipzig. Nicht selten erwuchsen solche Gründungen aus lokalen Initiativen. ${ }^{61}$ Allerdings mussten die Kirchen wiederholt eine unzureichende Förderung dieser Einrichtungen durch die Staatsregierung beklagen. ${ }^{62}$ Mittlerweile (2015) gibt es in Sachsen 57 anerkannte evangelische und sechs katholische Schulen. ${ }^{63}$

Neue kirchliche Ausbildungsstätten wurden gegründet: das Theologisch-Pädagogische Institut in Moritzburg 1997 für die Aus- und Fortbildung kirchlicher Mitarbeiter in der Gemeindepädagogik und im schulischen Religionsunterricht sowie für die fachliche und kollegiale Begleitung der aktiven Religionslehrer, aber auch anderer Fachlehrer, 1992 in Fortsetzung und Weiterführung der Ausbildungstätigkeit des dortigen Diakonenhauses die Evangelische Hochschule Moritzburg (Religionspädagogik, Gemeindediakonie und -pädagogik), 1991 die Evangelische Hochschule für Soziale Arbeit Dresden. Aus der 1949 gegründeten Kirchenmusikschule entstand 1990 die Hochschule für Kirchenmusik der Evangelisch-Lutherischen Landeskirche Sachsens. Die Evangelische Schule für Sozialwesen „Luise Höpfner“ Bad Lausick geht auf das 1953 gegründete Seminar für Kirchlichen Dienst zurück und bildet vor allem für die Tätigkeit in Kindergärten aus.

Geschlossen wurde hingegen das Theologische Seminar, seit 1990 Kirchliche Hochschule Leipzig. Es fusionierte 1992 mit der Theologischen Fakultät an der Leipziger Universität. Diese ist mit über 1.000 Studierenden, vor allem in den Pfarramts- und Lehramtsstudiengängen, eine der größten Evangelisch-Theologischen Fakultäten in Deutschland. ${ }^{64} 1993$ entstanden innerhalb der Philosophischen Fakultät der Technischen Universität Dresden Institute für
Evangelische und für Katholische Theologie, die vor allem für das wissenschaftliche Fachstudium künftiger Religionslehrerinnen und -lehrer zuständig sind.

Der intellektuellen Auseinandersetzung und dem Gespräch von Kirche und Gesellschaft dienen die Evangelische Akademie Meißen und die Katholische Akademie des Bistums Dresden-Meißen (u. a. das „Kathedralforum“ im Haus an der Kathedrale in Dresden). Das Bistum eröffnete 1992 im ehemaligen Rittergut Schmochtitz bei Bautzen das Bischof-BennoHaus. Die Evangelische Akademie Meißen bezog 1991 neue Räumlichkeiten auf dem Klosterhof St. Afra. Daneben gibt es eine Reihe von Einrichtungen der Erwachsenenbildung, darunter das Haus der Kirche in Dresden.

Christliche Vereine, die während der SEDHerrschaft verboten waren und, allerdings nicht unter ihrem ursprünglichen Namen, unter dem Dach der Kirche weiter existierten, gründeten sich neu - in der evangelischen Jugendarbeit zum Beispiel der Christliche Verein Junger Menschen (CVJM), der Jugendbund für Entschiedenes Christentum (EC) oder die Christlichen Pfadfinder. Evangelische und Katholische Studierendengemeinden können sich frei entfalten - Glaube, Bildung und Gemeinschaft sind Kernbereiche ihrer Arbeit. Aufgabe der Studierendenpfarrer ist auch die Kontaktpflege und das Vertreten kirchlicher Standpunkte im Bereich der Hochschule. ${ }^{65}$

Neu zu lernen war der kirchliche Umgang mit Medien und ihren Vertretern. ${ }^{66}$ In Rundfunk und Fernsehen wuchs mit Andachten, Gottesdiensten und thematischen Sendungen $\mathrm{zu}$ religiösen Themen die Präsenz der Kirchen. Mit eigenen Internetauftritten informieren sie über Entscheidungen, Positionen, Entwicklungen, christliches Leben und Veranstaltungstermine oder geben die Möglichkeit zu persönlichem Nachdenken über Glaubensfragen oder zur inneren Einkehr.

Die sächsische Landeskirche trat ebenso wie auch die Görlitzer Kirche und die Evangelische Kirche der Kirchenprovinz Sachsen 1991 der Evangelischen Kirche in Deutschland (EKD) sowie der Vereinigten Evangelisch-Lutherischen Kirche Deutschlands (VELKD) bei. Bereits 1990 war durch päpstliches Dekret die Berliner Bischofskonferenz aufgelöst und in die Deutsche Bischofskonferenz integriert worden. Sachsen ist das einzige ostdeutsche Flächenland, in dem seit der staatlichen Vereinigung größere gesamtdeutsche christliche Laienversammlungen stattfanden: 1994 ein Deutscher Katholikentag in Dresden und Deutsche Evangelische Kirchentage 1997 in Leipzig und 2011 


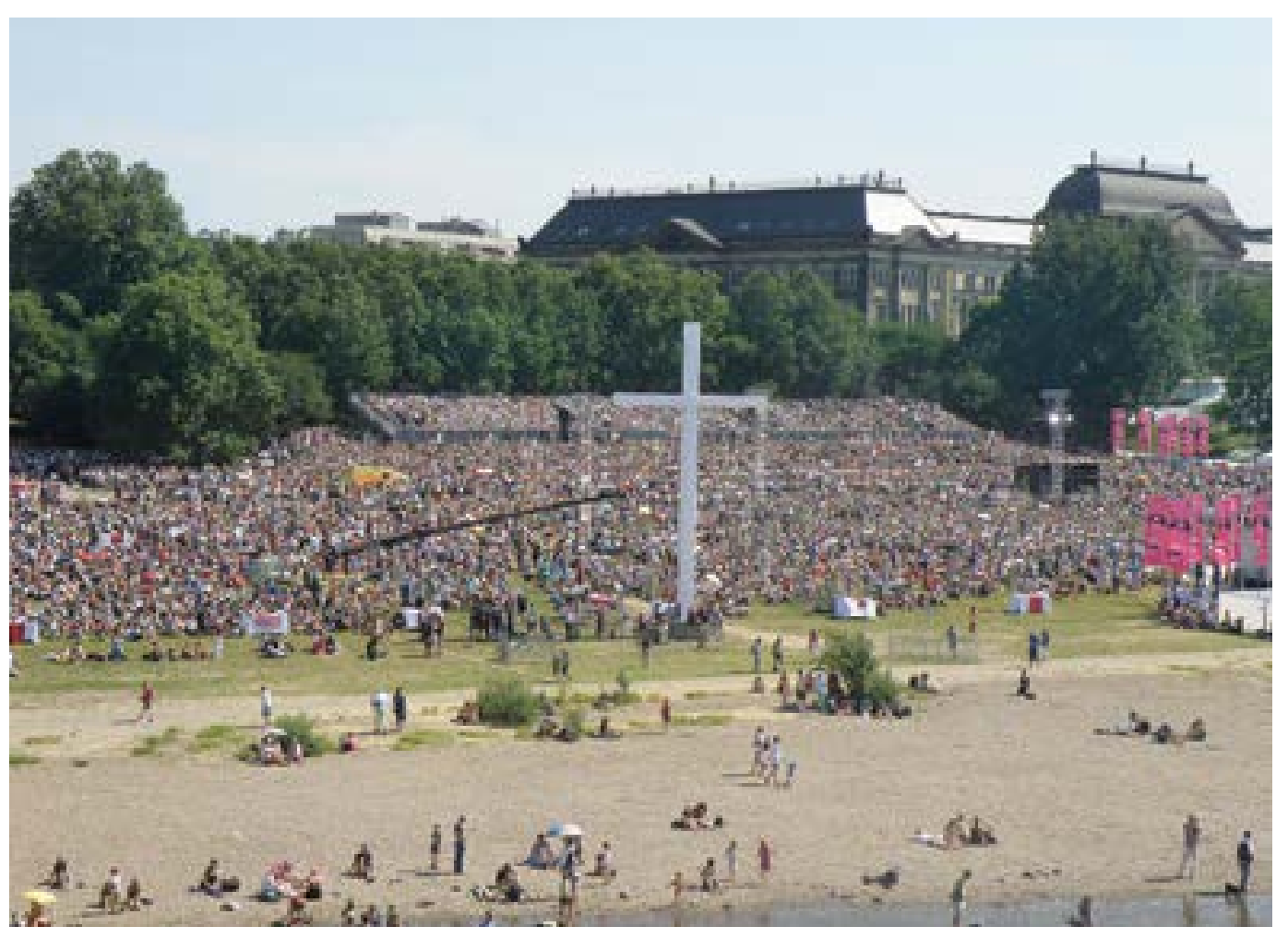

in Dresden. Der 100. Deutsche Katholikentag ist für 2016 in Leipzig geplant.

Deutlich erweitert wurde die soziale Tätigkeit der Kirchen: Der Einigungsvertrag zwischen der Bundesrepublik und der DDR sah im Bereich der Wohlfahrtspflege die Übertragung des sogenannten „dualen Systems“, der gleichberechtigten Kooperation von Staat und Kommunen mit freien Trägern, auf die östlichen Bundesländer vor. Auf der Grundlage des Subsidiaritätsprinzips delegiert der Staat Aufgaben an freie Träger und sorgt für deren finanzielle Unterstützung. Diakonisches Werk und Caritas wurden auch in Sachsen $\mathrm{zu}$ Spitzenverbänden der freien Wohlfahrtspflege und konnten ihre Tätigkeitsfelder deutlich ausweiten. Es kam zu Übernahmen, Neugründungen oder Erweiterungen von Kindergärten, Einrichtungen der Jugendhilfe, Krankenhäusern, Behindertenwohn- und -werkstätten, Senioreneinrichtungen, Pflegeheimen, Sozialstationen, Hospizdiensten und Palliativstationen. ${ }^{67}$ Bei einigen Kindergärten und Sozialstationen handelt es sich um ökumenische Einrichtungen. ${ }^{68}$

Durch neue gesellschaftliche Herausforderungen entstanden auch für die Kirchen zugleich neue Felder sozialen Handelns: Arbeitslosenprojekte und -initiativen, Schuldner- und Suchtkran-kenberatung, Obdachlosenarbeit, darunter auch vornehmlich von Ehrenamtlichen getragene ökumenische Nachtcafés in der dunklen Jahreszeit, und die Arbeit mit Asylbewerbern. Die sächsische Frühjahrssynode 1992 machte das „Zusammenleben mit Ausländern als Aufgabe unserer Kirche“ zu ihrem Hauptthema - es handelte sich vor allem um ehemalige Vertragsarbeiter, insbesondere aus Angola, Vietnam, Kuba, Moçambique, Studie-rende, Asylbewerber und sogenannte Kontingentflüchtlinge (Juden aus der ehemaligen Sowjetunion). Den Gemeinden sollte deutlich gemacht werden, dass Flucht oft mit Kriegen, der Verletzung von Menschenrechten und wirtschaftlicher Ungerechtigkeit zusammenhing. ${ }^{69}$ Alle hier genannten sozialkaritativen Angebote der Kirchen wurden und werden auch von Nichtchristen wahrgenommen. ${ }^{70}$ Das gilt auch für die Ehe- und Familienberatung. Kirchliche Schwangerenkonfliktberatungsstellen entstanden. Die 1991 von der katholischen Kirche initiierte, seit 1994 ökumenisch verantwortete „Woche für das Leben“ widmet sich der Frage des Schutzes von ungeborenem menschlichen Leben. Spätestens seit der Jahrtausendwende gewann das Bedenken bioethischer Problemstellungen in beiden Kirchen an Bedeutung, wie z. B. Fragen der Gentechnik ${ }^{71}$, der Embryonenforschung ${ }^{72}$ oder die Massentierhaltung ${ }^{73}$. Diakonie und Caritas beteiligen sich auch aufgrund ihres Selbstverständnisses als „Anwalt und Fürsprecher der Hilfsbedürftigen und Benachteiligten“ an sozialpolitischen Debatten. ${ }^{74}$
Deutscher Evangelischer Kirchentag 2011 in Dresden, Abschlussgottesdienst am Dresdner Elbufer Foto: Evangelisch-Lutherische Landeskirche Sachsens
67 Vgl. Greschat, Der Protestantismus (wie Anm. 55), S. 206; Betrachtungen (wie Anm. 23), S B 69; Bistum Dresden-Meißen, [Bautzen 2002], S. 17 f.

68 Vgl. Bistum Dresden-Meißen (wie Anm. 67), S. 13.

69 Vgl. Amtsblatt 1992, S. B 15-18.

70 Vgl. auch Gemeinde leben, in: Amtsblatt 2002, S. B 76.

71 Vgl. Jochen Bohl, Gentechnik als Thema für Gemeinde und Seelsorger, in: Amtsblatt 2000, S. B 35

72 Vgl. Kreß, Die Furcht (wie Anm. 26), S. B 58

73 Vgl. Verantwortlicher Umgang mit Nutztieren. Verlautbarung der 24. Ev.-Luth. Landessynode Sachsens vom 10. April 2000, in: Amtsblatt 2000, S. B 33-35.

$74 \mathrm{Vgl}$. Betrachtungen (wie Anm. 23), S. B 70.

75 Vgl. ebd., S. B 69

76 Vgl. http://www.diakonie-sachsen.de/wir-ueber-uns-fakten. html (Zugriff 12.8.2015). 
77 Vgl. Betrachtungen (wie Anm. 23), S. B 70.

78 Vgl. Jochen Bohl, Das Verhältnis von Kirche und Diakonie, in: Amtsblatt 1996, S. B 58.

79 Vgl. Kreß, Zur Lage (wie Anm. 13), S. B 97 f.

$80 \mathrm{Vgl}$. Bohl, Das Verhältnis (wie Anm. 78), S. B 60.

81 Text: Amtsblatt 2000, S. B 8. Zum Hintergrund vgl. Kirche in der Mitte der Gesellschaft (wie Anm. 5), S. B 18; Die zurückliegenden fünf Jahre (wie Anm. 42), S. B 85.

Die wiederaufgebaute evangelische Frauenkirche in Dresden Foto: Matthias Donath

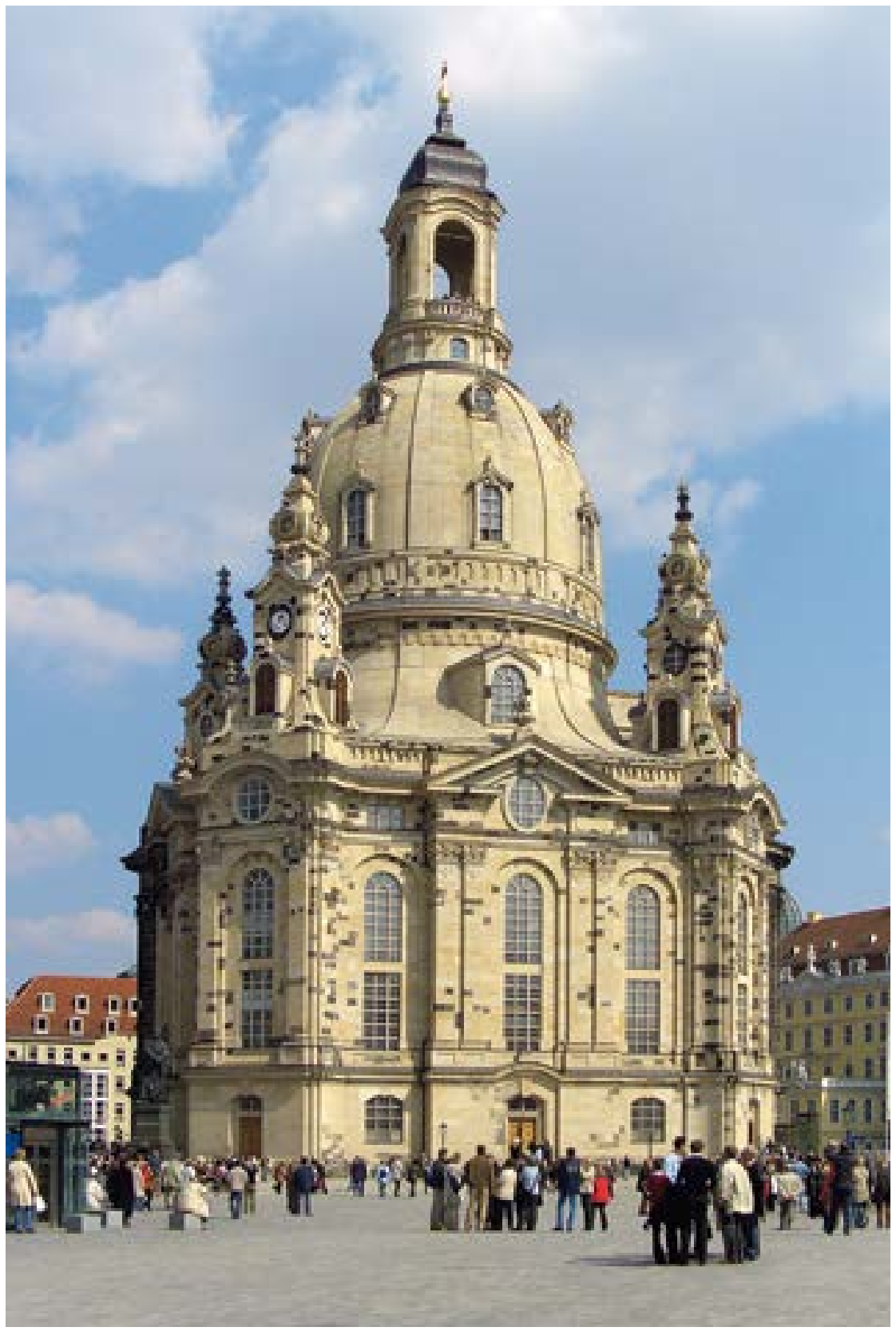

in den Gesundheitseinrichtungen. Bereits in der Mitte der 1990er Jahre kam es zu Einrichtungen erster Tochtergesellschaften, zum Beispiel in der Krankenhauswäscherei. Das war zum Beispiel mit Lohnsenkungen und einer Einschränkung des Kündigungsschutzes verbunden und blieb nicht ohne kritische Anfragen. ${ }^{80}$

Auch gesellschaftliche Probleme griffen die Kirchen auf: Auf ihrer Herbsttagung 1999 sprach sich die sächsische Landessynode aus sozialen und aus kulturellen Motiven angesichts einer geplanten Lockerung des Ladenschlussgesetzes gegen eine Aufhebung des Sonntagsschutzes aus. $^{81}$ Wiederholte Vorstöße beider Kirchen in dieser Frage folgten. Die Landessynode regte im Frühjahr 2006 einen innerkirchlichen Beratungsprozess an über Beiträge „zu einer sozial gerechten und ökologisch nachhaltigen Gestaltung der Globalisierung "82 1999 hatte die Synode eine Aussetzung der NATO-Luftangriffe in Jugoslawien gefordert ${ }^{83}$ und damit an das friedensethische Engagement in den 1980er Jahren angeknüpft.

Seit der Friedlichen Revolution setzte eine inwtensive kirchliche Bautätigkeit ein, darunter der Wiederaufbau der Frauenkirche in Dresden - die festliche Weihe fand am 30. Oktober 2005 statt. Mit der am 9. Mai 2015 geweihten Propsteikirche St. Trinitatisgibt es erstmals seit dem Zweiten Weltkrieg wieder eine katholische Kirche in der Leipziger Innenstadt. In Leipzig-Wahren entstand 1998 für den dortigen Konvent der Dominikanerinnen und Dominikaner St. Albert der erste Klosterneubau in den östlichen Bundesländern. 1992 ließen sich neben der romanischen Stiftskirche Heilig Kreuz in Wechselburg Benediktiner aus dem Kloster Ettal nieder. In dem neuen Kloster etablierte sich 2000 eine Familien- und Jugendbildungsstätte. Neben Bildungs- und Beratungsarbeit engagieren sich die sieben Klöster und ca. 20 Ordensniederlassungen in Sachsen in der Gefängnis-, Notfall- und Krankenhausseelsorge sowie im Hospizdienst und unterstützen die Arbeit in einzelnen Pfarrgemeinden. ${ }^{84}$

\section{Vergangenheitsaufarbeitung und -erinnerung}

Bereits Ende März 1990 erklärte Landesbischof Hempel vor dem Zentralausschuss des Ökumenischen Rates der Kirchen in Genf, auch Christen und darunter kirchenleitende Persönlichkeiten hätten durch ihr Verhalten das SEDRegime indirekt stabilisiert. ${ }^{85}$ Ende Oktober 1990 gestand er vor der sächsischen Landessynode ein, trotz aller Beharrlichkeit in Gesprächen mit Staatsfunktionären „nicht genug getan“ $\mathrm{zu}$ haben. Das galt zum Beispiel für die Vermeidung 


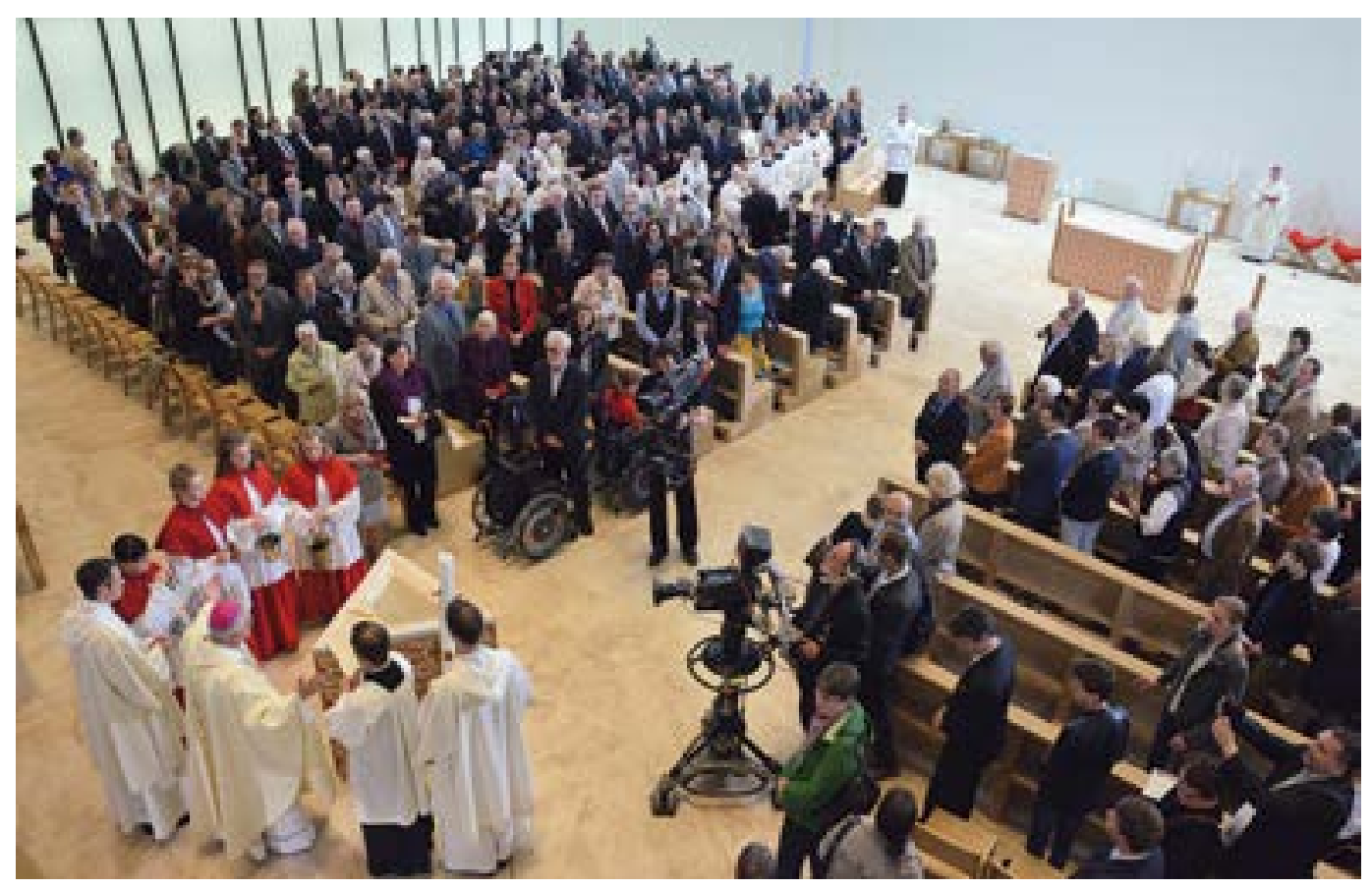

öffentlicher Proteste in Gegenwart westlicher Medien. Hempel sprach sich für Selbstreflexion und einen Austausch mit anderen über das persönliche Verhalten während der DDR-Zeit aus. „Verdrängungen und Legendenbildung erschweren den Weg in die Zukunft." ${ }^{\text {"86 }}$

In der Folgezeit wurde vor allem die Frage nach der Zusammenarbeit von ordinierten Pfarrern und haupt- und ehrenamtlichen kirchlichen Mitarbeitern mit dem Ministerium für Staatssicherheit (MfS) virulent. Nachdem Fälle aus Leipzig und auch Chemnitz öffentlich geworden waren, beantragten Landesbischof Hempel, das Kollegium des Landeskirchenamtes (LKA) und die überwiegende Mehrheit der sächsischen SuperintendentenbeiderStasi-Unterlagenbehörde ihre Überprüfung. ${ }^{87}$ Die Landessynode traf im März 1991 eine entsprechende Entscheidung für ihre Mitglieder, erweiterte diese jedoch nicht auf die sächsische Pfarrerschaft, da ein solcher Schritt „eine[r] grundsätzliche[n] Misstrauensäußerung gegen das [...] Ordinationsgelübde“ gleichkäme. ${ }^{88}$ Allerdings ermöglichte sie zugleich eine Wartestandsversetzung von Pfarrern und KirchenbeamteninFällen, wo ein begründeterVerdachtder Zusammenarbeit mit dem MfS vorlag. ${ }^{89}$ Hempel mahnte am 5. Oktober 1991 rechtsstaatlichen Kriterien genügende Dokumente, die über reine Karteikarten hinausgingen, und „überzeugende Kriterien “ für die Interpretation der Stasi-Akten an. ${ }^{90}$ Das Landeskirchenamt veranlasste schließlich doch die Überprüfung der Pfarrerschaft und der in einem unmittelbaren landeskirchlichen Dienstverhältnis stehenden Mitarbeiter, die Synode beschloss am 7. Oktober 1991 die freiwillige Überprüfung aller Mitarbeiter der Ge- meinden, Kirchenbezirke und sonstiger Einrichtungen der Landeskirche. ${ }^{91}$

Im April 1993 setzte die Kirchenleitung einen unabhängigen Bewertungsausschuss ein. Dieser erstellte Ende September 1995 seinen Abschlussbericht. ${ }^{92}$ Bei den Pfarrern kam es zu drei Dienstentlassungen und einer Kündigung sowie zu einigen Disziplinarstrafen. Das waren zwar, politikgeschichtlich bewertet, sehr geringe Zahlen, doch habe aufgrund des Vertrauensvorschusses, den Pfarrer auch unter Nichtchristen genießen, diese konspirative Zusammenarbeit mit dem MfS „der Kirche schweren Schaden zugefügt“, so das Gremium. Der Landeskirche warf es vor, verglichen mit dem staatlichen Bereich zu zögerlich und auch erst nach „Druck von unten" " mit der Überprüfung begonnen zu haben. Dadurch sei in der Öffentlichkeit der Eindruck entstanden, „die Kirchen hätten viel zu verbergen

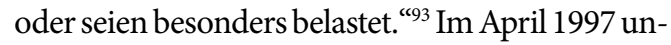
tersagte die Landessynode per Kirchengesetz der Pfarrerschaft jede geheimdienstliche Tätigkeit. ${ }^{94}$

Auch die NS-Vergangenheit beschäftigte die Kirchen. Anlässlich des 275-jährigen Bestehens des Katharinenhofes in Großhennersdorf, seit 1911 eine Einrichtung für schwerstbehinderte Kinder, wurde am 30. August 1996 auf dem Gelände der Einrichtung eine Stele zum Gedenken an die 223 durch die Nationalsozialisten von 1940 bis 1943 ermordeten Heimbewohner enthüllt. Zugleich wurden „Anteile gemeinsamer Schuld von Innerer Mission und Kirche" benannt. ${ }^{95}$ Der sorbische Priester Alois Andritzki, zuletzt Jugendseelsorger an der Dresdner Hofkirche und am 3. Februar 1943 im Konzentrationslager Dachau ermordet, wurde am 13. Juni 2011 seliggesprochen.
Weihe der neuen katholischen Propsteikirche St. Trinitatis in Leipzig am 9. Mai 2015 (c) Bistum Dresden-Meißen

82 Wirtschaften im Dienst des Lebens, in: Amtsblatt 2006, S. B 25.

83 Vgl. Kirchliches Jahrbuch 1999 , S. 473 .

84 Vgl. Bistum Dresden-Meißen (wie Anm. 67), S. 21-24

85 Vgl. Hempel, Kirche (wie Anm. 2), S. 212

86 Ebd., S. 220.

87 Vgl. ebd., S. 229 f.

88 Frühjahrstagung der Landessynode, in: Der Sonntag, Nr. 13 31.3.1991, S. 4.

89 Vgl. Kirchliches Jahrbuch 1992 S. 639.

90 Hempel, Kirche (wie Anm. 2), S. $229 \mathrm{f}$.

91 Vgl. Amtsblatt 1996, S. B 5.

92 Vgl. ebd., S. A 22.

93 Bericht des Stasi-Bewertungsausschusses der Ev.-Luth. Landeskirche Sachsens, ebd., S. B 5-9.

94 Vgl. Kirchliches Jahrbuch 1997, S. $475 \mathrm{f}$

95 Pfarrer Manfred Wugk, Aus der Ansprache zur Enthüllung der Stele am 30. August 1996, in: Amtsblatt 1996, S. B 104; vgl. auch Michael Ahrens, Tu Deinen Mund auf für die Stummen. 275 Jahre Katharinenhof Großhennersdorf, in: ebd., S. B 102 Folkert Ihmels, Was wird aus dieser „Ehe“?, in: ebd., S. $110 \mathrm{f}$. 


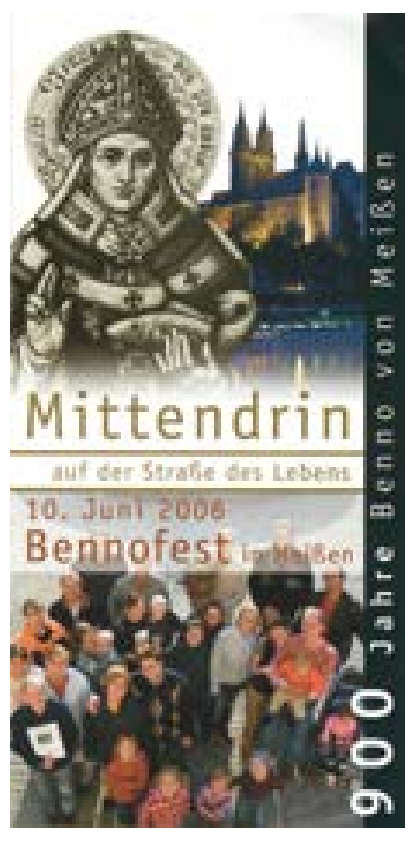

Programm zum Bennofest in Meißen 2009

96 Kirchliches Jahrbuch 1995, S. 501.

97 Vgl. Kirchliches Jahrbuch 1996, S. 528.

98 Vgl. Amtsblatt 1998, S. B 5561.

99 Ebd., S. B 55.

100 Ebd.

101 Vgl. dazu z. B. Kreß, Zur Lage (wie Anm. 13), S. B 96.

102 Vgl. z. B. Kirche in der Mitte der Gesellschaft (wie Anm. 5), S. B 15.

103 Vgl. Ihmels, An der Schwelle (wie Anm. 6), S. B 68.

104 Vgl. Statistisches Jahrbuch Sachsen 2 (1993), S. 129; 3 (1994), S. 132

105 Vgl. Hofmann, Angst (wie Anm. 39), S. B 46.

106 Vgl.StatistischesJahrbuchSachsen 6 (1997), S. 157.

107 Vgl.StatistischesJahrbuchSachsen 23 (2014), S. 145.

108 Vgl. Hempel, Kirche (wie Anm. 2), S. 231

109 Vgl. Ratzmann, Wozu jetzt noch Kirche (wie Anm. 38), S. B 57.

110 Vgl. Amtsblatt 1991, S. A 7.

111 Vgl. Wolfgang Ratzmann, Kirchliche Jugendarbeit zwischen neuen Hindernissen und künftigen Herausforderungen, in: Amtsblatt 1994, S. B 34.

112 Vgl. Kirchliches Jahrbuch 1996, S. 237.

113 Vgl. Volker Kreß, Kirche der Zukunft, in: Amtsblatt 1997, S. B 51 .

114 Vgl. Betrachtungen (wie Anm. 23), S. B 67
Bischof Joachim Reinelt und Landesbischof Volker Kreß gedachten am 5. April 1995 gemeinsam der „Vernichtung der Juden in Europa“.96 Beide Amtsträger gehörten $\mathrm{zu}$ den Schirmherren der 2001 abgeschlossenen Neuerrichtung der am 9. November 1938 zerstörten Dresdner Neuen Synagoge ${ }^{97}$, des ersten Neubaus eines jüdischen Gotteshauses in Ostdeutschland seit der Friedlichen Revolution.

Zum 60. Jahrestag der Reichspogromnacht erschien im landeskirchlichen Amtsblatt eine Arbeitshilfe. ${ }^{98}$ Beklagt wurden einleitend „schuldhaftes Reden und schuldhaftes Schweigen“ der deutschen Christenheit. Es bleibe „viel zu tun an Erinnerungsarbeit und theologischer Arbeit zu einer Neuorientierung aus der Heiligen Schrift". ${ }^{99}$ Das vor allem durch Zuwanderung aus Osteuropa bedingte Wachstum der Jüdischen Gemeinden eröffnete ein größeres Potential für persönliche Begegnungen zwischen Christen und Juden. Dem jüdisch-christlichen Dialog sowie Information, Aufklärung und Erinnerungsarbeit widmen sich die Jüdisch-Christliche Arbeitsgemeinschaft Leipzig sowie die Gesellschaften für Christlich-Jüdische Zusammenarbeit in Dresden und Zwickau. Sächsische Christen machten regen Gebrauch von der neuen Möglichkeit, nach Israel zu reisen..$^{100}$ 2006 gedachte das Bistum Dresden-Meißen des 900. Todestages seines Patrons, Bischof Benno. Ein Höhepunkt war ein ökumenischer Gottesdienst in Meißen. Die lutherische Landeskirche beging 2014 mit mehreren Veranstaltungen, darunter einem Landeskirchentag in Leipzig, die 475-jährige Wiederkehr der Einführung der Reformation in Sachsen.

\section{Innerkirchliche Entwicklungstendenzen}

1990 und in den Folgejahren blieb die insbesondere von westlicher Seite ${ }^{101}$ erwartete kirchlich-religiöse Renaissance - eine breite Rückkehr der Menschen in die Kirchen - aus. Die ostdeutsche Gesellschaft blieb mehrheitlich konfessionslos. Das wird nicht zuletzt am Fortbestehen der Jugendweihe mit sehr viel höheren Teilnehmerzahlen als in den westlichen Bundesländern deutlich. Mit verantwortlich für die mangelnde (Wieder-)eintrittsbereitschaft war ein religiöser Traditionsabbruch - die SEDMachthaber hatten christliche Inhalte und Bezüge aus dem Bildungs- und Medienbereich weitgehend verdrängt. Hinzu kam das verbreitete Gefühl, so wenigstens in einem Bereich dem westlichen Anpassungsdruck erfolgreich widerstehen zu können. ${ }^{102}$ Konfessionslosigkeit wurde zu einem Spezifikum ostdeutscher Identität. Hinzu kam und kommt in einer Zeit fortschreitender Individualisierungsprozesse eine gewisse Reserviertheit gegenüber Institutionen, Parteien und Verbänden und eine Zurückhaltung, sich festzulegen.

Es kam somit nicht $\mathrm{zu}$ den erhofften breiten Eintritten in die Kirchen, sondern zunächst zu einem Anstieg der Austrittszahlen. Die Mitgliederzahl der lutherischen Landeskirche sank zum Beispiel von 1,4 Millionen 1990 (1945 betrug die Zahl noch 4,3 Millionen ${ }^{103}$ ) auf 1,15 Millionen 1993, allerdings läst sich der Rückgang nicht nur auf Austritte (ca. 93.000) ${ }^{104}$ zurückführen. Für ganz Sachsen sank der Anteil der Kirchenmitglieder an der Gesamtbevölkerung von 26,5 Prozent Protestanten (1950 waren es noch 81,4 Prozent ${ }^{105}$ ) und 3,9 Prozent Katholiken $1994^{106}$ auf 19,9 Prozent Protestanten und 3,7 Prozent Katholiken Ende 2013 ${ }^{107}$. Seit 2010 lässt sich eine gewisse Stagnation der Werte feststellen, ohne dass weitere größere Rückgänge $\mathrm{zu}$ verzeichnen sind.

Der Kirchenbesuch war bald wieder auf dem Stand der Zeit vor dem Herbst $1989 .{ }^{108}$ Manche Gemeindegruppen und -kreise wurden deutlich kleiner oder lösten sich gar auf ${ }^{109}$ - eine Folge eines verbreiterten auch außerkirchlichen Angebots sowie der gesellschaftlichen Umstrukturierungen, die das Zeitbudget vieler Menschen schrumpfen ließen. Die Positionierung der christlichen Gemeinden in einer „pluralistischen Konsum- und Freizeitgesellschaft" war auch das Thema eines ökumenischen Pastoralkollegs in Krummenhennersdorf bei Freiberg Anfang April 1991. ${ }^{110}$ Der kirchliche Umstrukturierungsprozess und die stärkere Bürokratie, zum Beispiel für die Beantragung von Fördermitteln, banden zudem viele Kräfte, die für die eigentlichen Aufgaben nicht oder sehr viel weniger als zuvor zur Verfügung standen. ${ }^{111}$

Weiterhin waren die ostdeutschen Landeskirchen und Bistümer auf westliche Finanzhilfen angewiesen. In der Mitte der 1990er Jahre kam es zu einem Rückgang der Kirchensteuereinnahmen. ${ }^{112}$ Das hing zusammen mit weiteren Abwanderungen in die westlichen Bundesländer, der zunehmenden Überalterung der Gemeinden und der hohen Arbeitslosigkeit. ${ }^{13}$ Hinzu kamen bald auch Veränderungenin derSteuergesetzgebung ${ }^{114}$ DieseEntwicklung führte seit Mitte der 1990er Jahre zu größeren Sparzwängen. ${ }^{115}$ Trotz aller Bemühungen um Sozialverträglichkeit kam es in der Landeskirche auch zu einzelnen Entlassungen. ${ }^{116}$ Für junge Theologen gab es hier erstmals Wartelisten. ${ }^{117}$ Neben dem Stellenabbau wurden auch neue Steuerungsinstrumente für die Zuweisungen von Finanzen entwickelt. ${ }^{118}$ Ein Strukturpapier 1997 brachte Kirchspiele ins Gespräch ${ }^{119}$ letztlich überließ man es nach heftigen Kontroversen den Kirchgemeinden, ob sie sich mit räumlich benachbarten Gemeinden zu einem Kirchspiel als einer Gesamtkirchengemeinde mit einem 


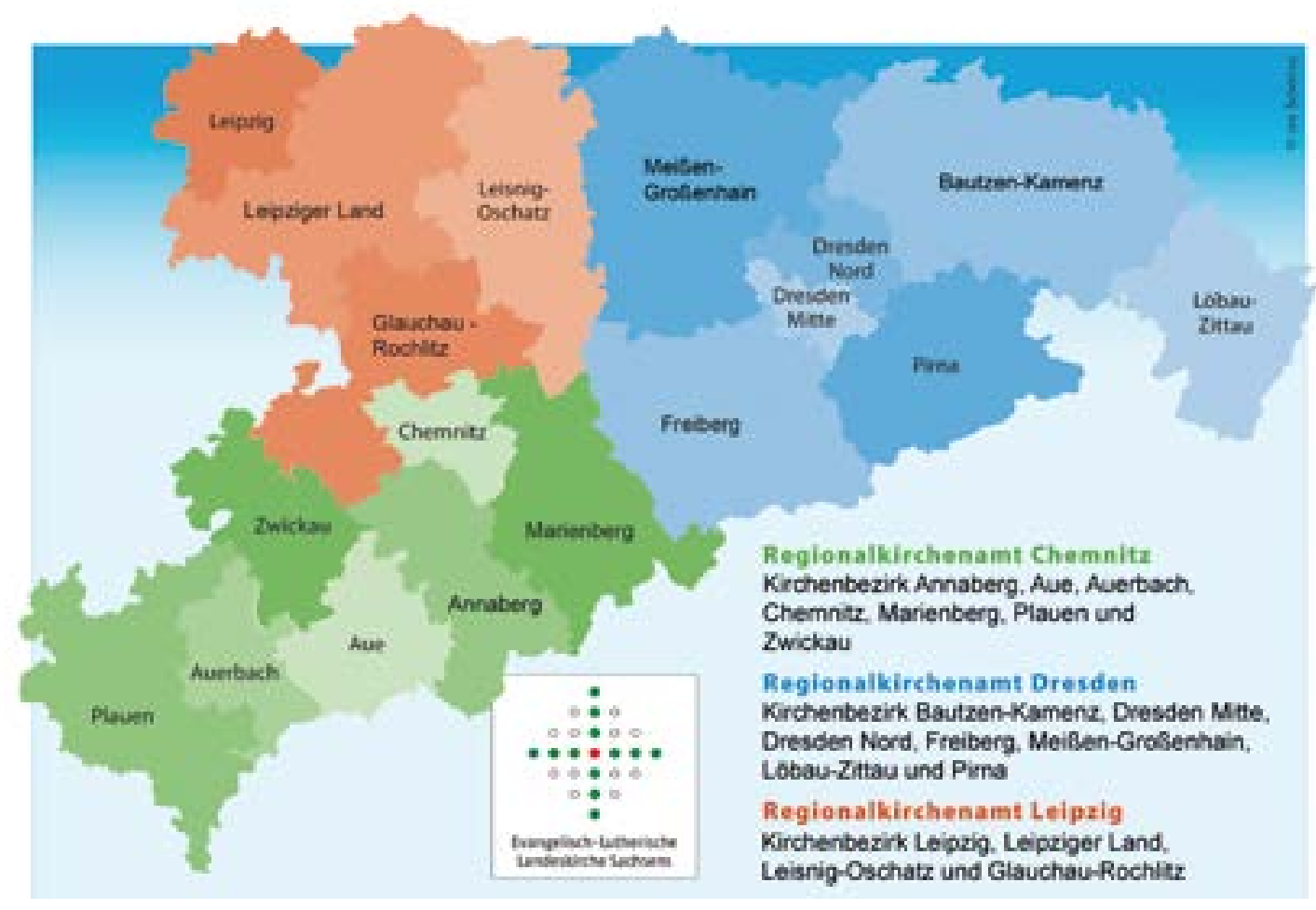

gemeinsamen Kirchenvorstand zusammenschließen oder eine lockerere Schwesterkirchverbindung eingehen. ${ }^{120}$ Hinzu kam eine Reduzierung der Kirchenbezirke von 24 auf 18 zum 1. Januar 2013. ${ }^{121}$ Auch die Leitung des Bistums Dresden-Meißen leitete 2001 eine Strukturreform ein. Hier kam $\mathrm{zu}$ der negativen Mitgliederentwicklung ein zunehmender Priestermangel hinzu. Bis 2010 war eine Reduzierung der Pfarreien von 165 auf etwa 95 vorgesehen. Wie in der Landeskirche setzt man verstärkt auf das Ehrenamt - man möchte „Menschen ermuntern, Verantwortung zu übernehmen, damit Kirche lebendig bleibt. " ${ }^{\text {122 }}$

Allerdings waren und sind am Heiligabend die Kirchen auch im Osten Deutschlands stark gefüllt, und das nicht nur von Mitgliedern, eine Deutung dieses Phänomens ist ein Bedürfnis der Menschen nach feierlichen Orten. ${ }^{123}$ In den Tagen nach den Terroranschlägen in den USA am 11. September 2001 gab es eine starke Inanspruchnahme geistlicher kirchlicher Angebote. ${ }^{124}$ Wie auch während der Elbüberschwemmungskatastrophe im August 2002 waren offensichtlich die rituelle und die Deutungskompetenz der Geistlichen bei der Bewältigung des medial oder direkt Erlebten gefragt. ${ }^{125}$ Das gilt auch für die Mahnwachen und Friedensgebete, die Anfang 2006 in Leipzig für zwei im Irak entführte aus der Stadt stammende Ingenieure stattfanden, und den nach ihrer wohlbehaltenen Rückkehr von über 2.000 Menschen besuchten Dankgottesdienst in der Nikolaikirche am 8. Mai 2006. ${ }^{126}$

Kirchliche Bildungseinrichtungen und -angebote, Kulturveranstaltungen, vor allem die in Sachsen traditionell besonders stark verwurzelte Kirchen- musik, und Führungen durch kirchliche Gebäude werden auch von Nichtchristen wahrgenommen. ${ }^{127}$ Konfessionslose beteiligen sich aktiv an kirchlichen Chören ${ }^{128}$ und engagieren sich bei und für den Aufbau und die Sanierung von Kirchen sowie die Instandsetzung von Orgeln. ${ }^{129}$

Die bereits während der DDR-Zeit bestehende innerkirchliche Differenzierung in eher lutherischkonfessionalistisch, neupietistisch-evangelikal und charismatisch geprägte Gruppen, Gemeinden und Theologen auf der einen Seite und theologisch Liberale und gesellschaftsethisch Orientierte auf der anderen Seite führte in der Landeskirche in den frühen 1990er Jahren zu Kontroversen über den Schutz ungeborenen Lebens oder die Stellung und Rechte von Mann und Frau in Kirche und Gesellschaft. Aufgrund eines unterschiedlichen Verständnisses von der Auslegung der Bibel konnte hier kein Konsens erzielt werden. ${ }^{130}$ Der äußere Druck durch das SED-Regime, der auch gemacht hatte, bestand nicht mehr. ${ }^{131}$ Diese Auseinandersetzungen bedeuteten innerkirchlich einen großen Kräfteverschleiß, sie kosteten „aber auch viel an überzeugender Ausstrahlung nach außen", erklärte Landesbischof Volker Kreß 1995. ${ }^{132}$ Er konstatierte eine „Tendenz [...] zu einfachen, angeblich eindeutigen Antworten “. ${ }^{133} \mathrm{Zu}$ den theologischen Meinungsverschiedenheiten kamen politische hinzu. Auch in Kirchgemeinden gestaltete sich das Zusammenleben nicht selten spannungsreicher. ${ }^{134}$

Ab 2012 spitzten sich die Konflikte nochmals zu - diesmal ging es um die christliche Bewertung von Homosexualität angesichts der Frage nach eine innerkirchliche Geschlossenheit erforderlich
Übersichtskarte der EvangelischLutherischen Landeskirche Sachsens () Evangelisch-Lutherische Landeskirche Sachsens

115 Vgl. Dietrich Mendt, Angst um die Kirche?, in: Amtsblatt 1996 S. B 56.

116 Vgl. Betrachtungen (wie Anm. 23), S. B 68.

117 Vgl. Kreß, Zur Lage (wie Anm. 13), S. B 97.

$118 \mathrm{Vgl}$. resümierend Gemeinde leben (wie Anm. 70), S. B 75.

119 Vgl. auch Nur keine Angst, wenn alles anders wird. In terview mit Gudrun Lindner, Präsidentin der Sächsischen Landessynode, in: Der Sonntag, Nr. 45, 9.11.1997, S. 5.

120 Vgl. Die zurückliegenden fünf Jahre (wie Anm. 42), S. B 87

121 Vgl. Bericht der Kirchenleitung 2014, S. 2 (http://www. evlks.de/doc/VL $08 \mathrm{KL}$ Bericht2014.pdf); Zugriff 11.8.2015)

122 Bistum Dresden-Meißen (wie Anm. 67), S. 13.

123 So Kreß, Wenn aber kommen wird (wie Anm. 25), S. B 82.

124 Vgl. ebd., S. B 83.

125 Vgl. Gemeinde leben (wie Anm. 70), S. B 76.

126 Vgl. auch Jochen Bohl, Das Eigene stärken und die Chancen nutzen, in: Amtsblatt 2006, S. B 46.

127 Vgl. auch Gemeinde leben (wie Anm. 70), S. B 79

128 Vgl. Jochen Bohl, Zeitenwende, in: Amtsblatt 2009, S. B 75.

129 Vgl. auch Über-Lebensfragen. Perspektiven der Kirche zu Fragen der Zukunft unserer Gesellschaft, in: Amtsblatt 2004, S. B 6. 


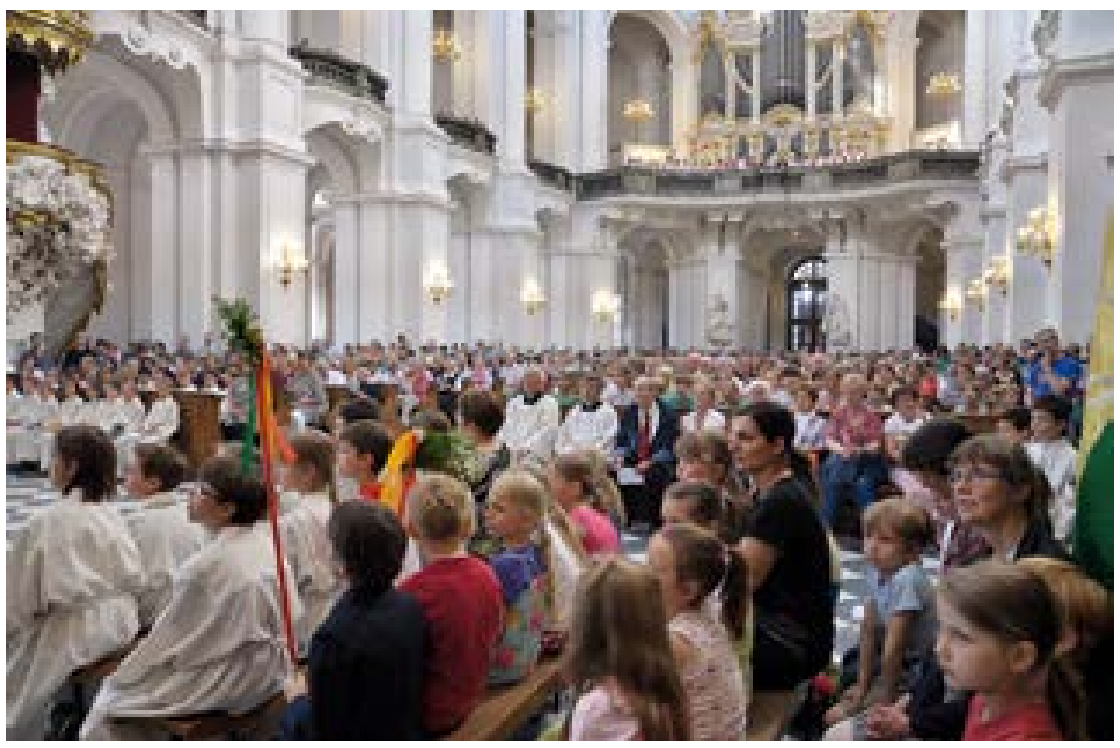

Fronleichnamsprozession in der katholischen Kathedrale

St. Trinitatis in Dresden (ehemals katholische Hofkirche), 2015 (C) Bistum Dresden-Meißen

130 Vgl. Hempel, Kirche (wie Anm. 2), Leipzig 1994, S. 257.

131 Vgl. auch Ihmels, Wünsche (wie Anm. 34), S. B 13.

132 Volker Kreß, Auf der Suche nach Gewißheit, in: Amtsblatt 1996, S. B 1

133 Kirchliches Jahrbuch 1997, S. 81

134 Vgl. Ratzmann, Kirchliche Jugendarbeit (wie Anm. 111), S. B 34.

135 Vgl. http://www.evlks.de/doc Bericht zum Gespraechsprozess_ueber_das_Schrift-_und Kirchenverstaendnis Endfassung.pdf, S. 1-4 (Zugriff 11.8. 2015) ; auch Bericht der Kirchenleitung 2014, S. 5 (http:/ www.evlks.de/doc/VL 08 KL-Bericht2014.pdf); Zugriff 11.8.2015)

136 Vgl. Andreas Roth, Gespräch ohne Prozess, in: Der Sonntag, Nr. 16, 19.4.2015, S. 1.

137 Uwe Naumann, Keine Erschütterungen, in: Der Sonntag, Nr. 6, 10.2.2013, S. 8

Morgenandacht mit Posaunenbläsern Foto: Rainer Oettel

Autor

Prof. Dr.

Gerhard Lindemann

TU Dresden

Institut für

Evangelische Theologie 01062 Dresden dem Zusammenleben Gleichgeschlechtlicher in sächsischen Pfarrdienstwohnungen aufgrund des Pfarrerdienstgesetzes der EKD aus dem Jahr 2010, das solche Möglichkeiten auch als Konsequenz aus dem staatlichen Lebenspartnerschaftsgesetz von 2001 ausdrücklich vorsieht. Obwohl die sächsische Kirchenleitung am 20./21. Januar 2012 eine stark modifizierte Fassung der EKDRegelung beschlossen hatte - demnach ist ein solcher Schritt nur in Einzelfällen möglich, überdies ist die „einmütige Zustimmung des zuständigen Kirchenvorstandes" erforderlich -, kam es zu scharfen Kontroversen. 144 sächsische Kirchenvorstände unterzeichneten neben vielen Einzelpersonen die gegen den Inhalt dieses Beschlusses gerichtete „Markersbacher Erklärung“
- und am 30. Januar 2012 kam es zur Gründung einer Sächsischen Bekenntnis-Initiative. ${ }^{135}$ Es ging bis hin Austrittsdrohungen aus der Landeskirche. Ein dreijähriger Gesprächsprozess konnte eine solche Entwicklung zwar verhindern, jedoch blieb es weitgehend bei den gegensätzlichen Positionen, erweitert nun zum Beispiel um Infragestellungen der historisch-kritischen Auslegung der Bibel. ${ }^{136}$ Das Konfliktpotential ist vermutlich auch generell mit bedingt durch eine Verstärkung des Stadt-Land-Gefälles in Sachsen aufgrund der recht positiven wirtschaftlichen Entwicklung der Großstädte Leipzig und Dresden und der gleichzeitigen Schwächung ländlicher Regionen sowie mentalitätsmäßiger Unterschiede zwischen urbanen und ländlichen Gebieten.

Am 31. Mai 2015 wählte die Landessynode Carsten Rentzing, Pfarrer in Markneukirchen im Vogtland und ein Unterstützer der Bekenntnis-Initiative, in einer Stichwahl im sechsten Wahlgang mit knapper Mehrheit zum neuen sächsischen Landesbischof. Rentzing, ein promovierter Theologe, hatte während des Gesprächsprozesses im Blick auf das Bibelverständnis von einem "garstigen Graben“ zwischen akademischer und "Gemeindetheologie“ gesprochen und ersterer dafür die Verantwortung zugewiesen. Er stieß damit auf heftigen Widerspruch, unter anderem von Landesbischof Jochen Bohl. ${ }^{137}$ Das Wahlergebnis ist Ausdruck einer tiefen Spaltung innerhalb der Landeskirche, bietet womöglich aber zugleich Chancen zu einer gewissen Befriedung, da die sächsische Kirchenverfassung das Bischofsamt als ein kirchliches Einheitsamt versteht. Von daher leitet sich der Auftrag eines sächsischen Landesbischofs ab, integrativ zu wirken.

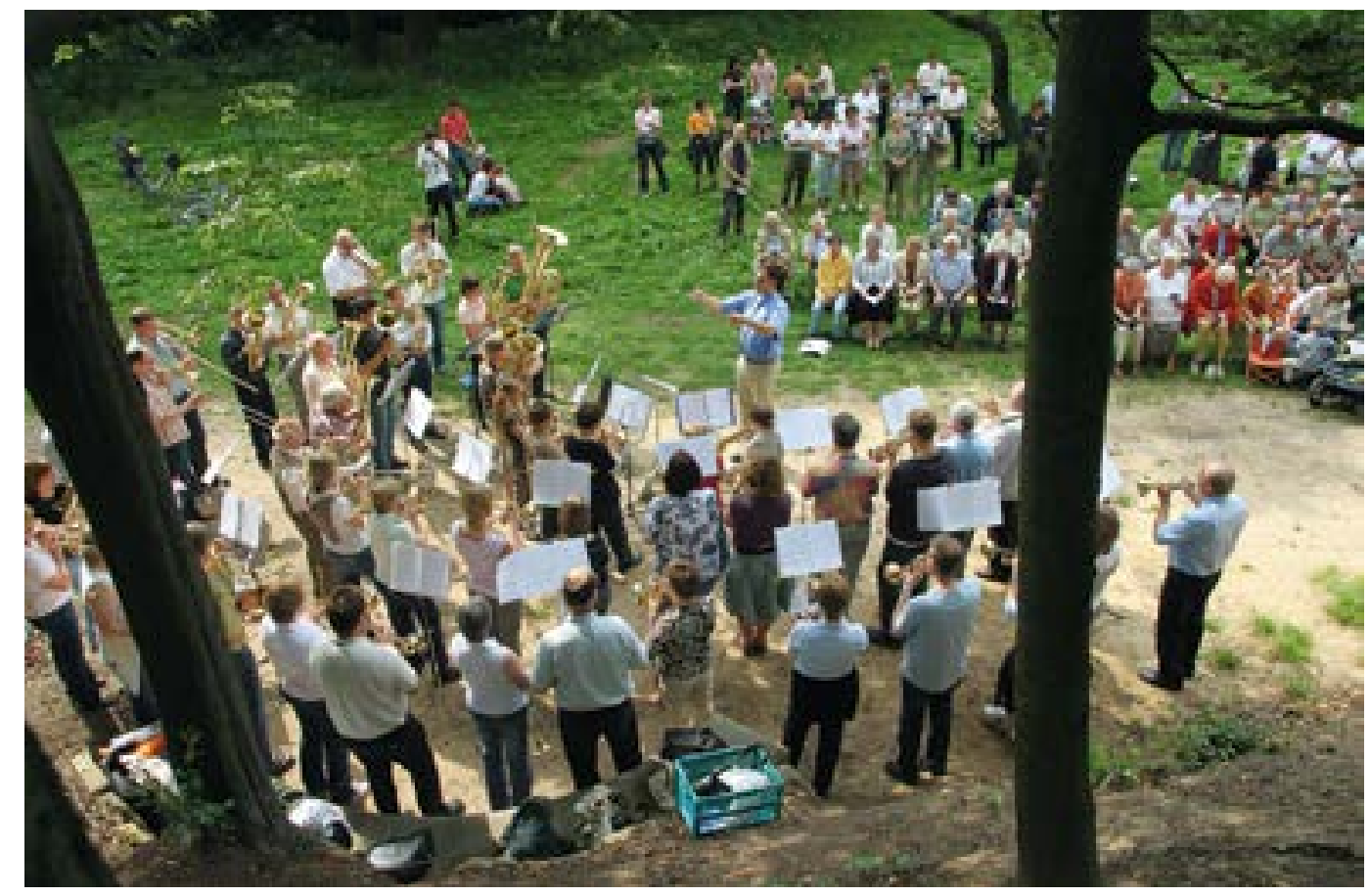

